University of Nebraska - Lincoln

DigitalCommons@University of Nebraska - Lincoln

Sociology Department, Faculty Publications

Sociology, Department of

$12-2016$

\title{
Relocation Redux: Labrador Inuit Population Movements and Inequalities in the Land Claims Era
}

\author{
Kirk Dombrowski \\ University of Nebraska - Lincoln, kdombrowski2@unl.edu \\ Patrick Habecker \\ University of Nebraska-Lincoln, phabecker2@unl.edu \\ G. Robin Gauthier \\ University of Nebraska-Lincoln, ggauthier3@unl.edu \\ Bilal Khan \\ University of Nebraska - Lincoln, bkhan2@unl.edu \\ Joshua Moses \\ Haverford College, jmoses@haverford.edu
}

Follow this and additional works at: https://digitalcommons.unl.edu/sociologyfacpub

Part of the Family, Life Course, and Society Commons, Indigenous Studies Commons, Social and

Cultural Anthropology Commons, and the Social Psychology and Interaction Commons

Dombrowski, Kirk; Habecker, Patrick; Gauthier, G. Robin; Khan, Bilal; and Moses, Joshua, "Relocation Redux: Labrador Inuit Population Movements and Inequalities in the Land Claims Era" (2016). Sociology Department, Faculty Publications. 715.

https://digitalcommons.unl.edu/sociologyfacpub/715

This Article is brought to you for free and open access by the Sociology, Department of at DigitalCommons@University of Nebraska - Lincoln. It has been accepted for inclusion in Sociology Department, Faculty Publications by an authorized administrator of DigitalCommons@University of Nebraska - Lincoln. 


\title{
Relocation Redux
}

\section{Labrador Inuit Population Movements and Inequalities in the Land Claims Era}

\section{by Kirk Dombrowski, Patrick Habecker, G. Robin Gauthier, Bilal Khan, and Joshua Moses}

Online enhancements: appendix.

\begin{abstract}
The importance of community relocation experiences for aboriginal land claims movements is well documented; the role played by successful land claims in prompting ongoing out-migration is not. Data collected in 2011 on the lives of migrants are used to test three hypotheses: $\mathrm{H}_{1}$, Inuit leaving the land claims area for a nearby nonaboriginal city show markedly different social outcomes based on the length of time since migration; $\mathrm{H}_{2}$, these social outcomes map onto patterns of intergroup boundaries in their new communities; and $\mathrm{H}_{3}$, both of these outcomes are better explained by migration patterns after the land claims than by the ethnic/racial exclusion that has been the focus of past research on inequality in the region. This analysis takes advantage of social network techniques used to study hard-to-reach populations, showing how these methods can be used to address broader questions of community structure and cohesion during rapid social change. Conclusions focus on the experiences of migrants on the margins of sending and receiving communities and what they can tell us about the role played by aboriginal land claims in the culture politics of industrial resource extraction.
\end{abstract}

Indigenous land claims are closely associated with individual and household relocation in Arctic ethnography but are rarely seen as operating in conjunction. Although the centrality of relocation experience to the land claims movements of many communities is well documented, the role played by successful land claims in prompting postclaims out-migration is seldom a subject of ethnographic notice. This paper uses data collected in 2011 to document the lives of migrants after leaving an indigenous land claims areas in eastern Canada. On virtually all measures, they are among the most marginal members of their new towns. Here we explore what this experience can tell us about the role played by land claims, as currently conceived

Kirk Dombrowski is Professor in the Department of Sociology at the University of Nebraska-Lincoln (711 Oldfather Hall, Lincoln, Nebraska 68502, USA [kdombrowski2@unl.edu]). Patrick Habecker is a doctoral student in the Department of Sociology at the University of Nebraska-Lincoln (711 Oldfather Hall, Lincoln, Nebraska 68502, USA). G. Robin Gauthier is a Postdoctoral Fellow at the Reach Lab (Research, Evaluation, and Analysis for Community Health) at the University of Nebraska-Lincoln (209 Benton Hall, Lincoln, Nebraska 68588-0623, USA). Bilal Khan is Professor in the Department of Sociology at the University of Nebraska-Lincoln (728 Oldfather Hall, Lincoln, Nebraska 68502, USA). Joshua Moses is Assistant Professor in the Department of Anthropology at Haverford College (370 Lancaster Avenue, Haverford, Pennsylvania 19041, USA). This paper was submitted 23 VI 15, accepted 25 XI 15, and electronically published 3 XI 16. within the larger process of industrial resource extraction in the North, in the ongoing transformation of culture politics in the Arctic.

Earlier mid-twentieth-century relocations of entire Inuit communities in Canada were the source of well-known social dislocation and suffering. As documented by Marcus (1991, 1995), Tester and Kulchyski (1994), and, for Labrador, a host of more specific studies (Ben-Dor 1977; Brice-Bennett 1977, 1994; Burns 2006; Damas 2004; Kennedy 1977; Samson 2003; Sider 2006), the confused and often contradictory process of Inuit community relocations involved a hodgepodge of plans to lay claim to far northern regions, consolidate government services to dispersed settlements, and facilitate assimilation throughout the Arctic. Few of these aims were met, and the problems created for individuals and communities lingered for decades. In Labrador, the social inequalities and intracommunity boundaries that resulted from the Hebron relocation not only remain well into the present but affect the descendants of relocatees as well-fostering intergenerational patterns of social marginality and isolation, such that many of the social problems suffered by relocatees are also felt by their children (Dombrowski et al. 2013c, 2014; for a discussion, see Whitbeck et al. 2004). Recognition of the short- and long-term damage done has prompted a number of apologies by various entities within the Canadian government-including federal-level apologies for the "High Arctic" relocations and apologies by the government of New- 
foundland and Labrador for the relocation of the residents of Hebron and Okak. Needless to say, with so much remaining unaddressed in the wake of these changes, official attempts at reconciliation have received a mixed reception within Canada's indigenous community (Amagoalik 2008; James 2008; Wakeham 2012).

A more historical view would note that these apologies normally follow periods of highly visible aboriginal activism and, perhaps as importantly, a push by the government of Canada to harness northern peoples' desire for autonomy to their own mineral and energy development goals in a rapidly shifting Arctic (Dombrowski 2008, 2014; Scott 2011; Sider 2014; Tester and Kulchyski 1994). Indeed, for many Inuit, redress (in the form of land settlement rights and a realistic claims process) has remained a higher priority than formal apologies. Through land claims, indigenous northern residents hope that sovereignty and self-government will prevent forced relocation from happening again and further that locally directed economic development will make up for the difficult economic conditions prompted by settlement/resettlement (Duffy 1988; Hicks and White 2000). Nunatsiavut, the Inuitgoverned region of Labrador, is largely a result of this myriad set of processes. It was created in 2005-2006, less than a decade after its larger and better-known predecessor of $\mathrm{Nu}$ navut (Brice-Bennett 1977; Cunsolo Willox et al. 2012; Procter 2012), following years of local activism, provincial recognition of past resettlement wrongs, and the discovery of large nickel and copper resources in the claims area. Optimism remains high among Labrador Inuit for the benefits that can and should follow from the 2005-2006 land settlement agreement. But a range of factors have dampened the initial enthusiasm, including a nearly 2-year strike/lockout at the nearby Voisey's Bay nickel mine.

In general terms, large-scale resource extraction represents an important issue that is also of primary concern for contemporary anthropologists, who recognize that such issues frequently involve state manipulation of traditional anthropological subjects - indigenous peoples whose claims to land, sovereignty, self-determination, and being have, since the earliest years of colonialism, been tethered to the sorts of uses that external states and actors find for them (Ballard and Banks 2003). More recently, however, such groups have been subject to and engaged in a new praxis of indigeneity that reframes aboriginal peoples' claims to life and land as claims to specific pieces of property and the resources they contain, over which they can be made owners and thus enter into relationships with development forces (Dombrowski 2002). This process is akin to the "recognition" discussed by Charles Taylor (1994) and others, but in the case of indigenous land claims it is far more closely tied to the vagaries of global political economy (Jackson and Warren 2005; Larsen 2015), which serves to confine local choices to specific channels of engagement most often from positions of community economic need (Lea 2012).

As Kulchyski (2005) points out, steps to genuine selfgovernment by Inuit and First Nations people in Canada have been frustrated and slowed by a number of extracommunity forces. As a result, for many communities in and beyond Labrador, land claims have not brought the marked change in social conditions that many residents had hoped for (Cunsolo Willox et al. 2012; Procter 2012). This holds especially true for those communities in Nunatsiavut (and indeed throughout northern Canada), where large-scale mining began rapidly following land settlement agreements, but trickle-down benefits have largely failed to reach more marginal households (Dombrowski et al. 2013a). Indeed, land claims have left many households within land claims areas in worse conditions than they experienced before the agreements, as failed expectations and the rising social costs of global inclusion combine with inadequate personal/household resources and a rapidly changing social environment that requires new skills and social forms (Dombrowski et al. 2013c, 2014).

Inuit communities throughout northern Canada and Alaska continue to suffer disproportionate health issues and high levels of both food and economic vulnerability (KermodeScott 2005; Kirmayer, Boothroyd, and Hodgins 1998; Nguyen et al. 2003; Oliver, Peters, and Kohen 2012; Peters 2010; Wilkins et al. 2008). Community control over local governance and community reproduction has been found to act as a hedge against suicide - a common problem in many Inuit communities (Chandler and Lalonde 1998; Chandler and Proulx 2006; Chandler et al. 2003) — but similar results have not been seen for related problems, such as substance abuse, food insecurity, family and household violence/abuse, crime, and general physical and emotional health. The reasons for the latter are unclear. Elsewhere we have speculated that internal inequalities that predate the land claims are fostered and exaggerated by the land claims and development processes themselves (Dombrowski 2007, 2014). These speculations stem from the fact that land claims processes valorize elements of local lifestyle and tradition that are at once celebrated by official recognition and subsequently undermined by the development process that follows such recognition (Cowlishaw and Lea 2010; Li 2014). Even as traditional subsistence and land-based practices lay the groundwork for the justification and delimitation of claims (Hunn et al. 2003), mineral, energy, and other natural resource extraction degrades the sustainability of those lifestyles and livelihoods via a process of environmental damage, population concentration, competing housing needs from the influx of new (development and self-government) workers, and a general process of inflation that goes with a more thorough immersion in a global cash economy (Austin-Broos 2009). The result is a conflicted social and personal milieu where "culture" is at once an important feature of local political life and increasingly difficult to sustain (Dombrowski 2014). As Gerald Sider (2014) has pointed out, one implication of this is that for many individuals who find themselves only marginally incorporated in the emerging political economy, the present is primarily figured as a time of "loss."

In describing this transition for communities in Alaska, we noted that one reaction to this process is the silent out- 
migration of significant numbers of individuals from those areas with successful land claims (Dombrowski 2002, 2007). This process was noted ethnographically nearly 50 years ago (Chance 1960, 1990) but has received discouragingly little attention from ethnographers of northern communities. Here we discuss research whose strategy is similar to that employed by Chance many decades ago examining the conditions that aboriginal individuals find themselves in after leaving land claims areas, and we ask what this can tell us about the land claims process as it is experienced by at least some segments of the community. As such, this paper takes up an issue that lies between the two processes introduced above - that is, between the modern Arctic land claims ongoing since the 1970s (and reaching their peak in Labrador in the past decade) and historic relocations of Arctic communities. The argument is that the latter, completed by the 1960s, finds haunting parallels in the outmigrations of residents of land claims area today. We make this argument for the specific example of Labrador, Canada, by focusing on former coastal residents from the Nunatsiavut land claims area who left for the nearby local city of Happy Valley following the Labrador Inuit Land Claims Agreement of 2005-2006.

This focus will strike northern ethnographers as unusual. As we have argued elsewhere, this likely has to do with the frequently too narrow "community focus" of classical ethnography, whereby those who leave the community subsequently disappear from ethnographic accounts, as though neither their new lives nor the reasons for their departure have anything to teach us about the communities they depart (Dombrowski 2007, 2008). In Alaska and northern Canada, much ethnographic work continues to focus on remote and isolated communities (for a recent review, see King and Furgal 2014). The process of aboriginal incorporation, migration, and land claims, however, has quietly emerged as a general concern among those working with aboriginal peoples elsewhere (for examples from Australia, see Austin-Broos 2011; Cowlishaw and Lea 2010; Lea 2012). Despite this growing concern, the topic remains a minority position in larger discussions of indigeneity in the North (for important exceptions, see Abele, Falvo, and Hache 2010; Christensen 2012; Glasser 1997; Kishigami 2008; Nguyen et al. 2003).

As a partial remedy to this, we performed ethnographic and social network research in two Labrador communities. The first, Nain, is one of the larger coastal, predominantly Inuit communities located within Nunatsiavut; the second, Happy Valley-Goose Bay (HVGB), is a predominantly nonindigenous community located several hundred miles to the south of Nain and outside the Labrador Inuit land claims area. ${ }^{1}$ Our focus, in both cases, was on patterns of informal connection within communities, as these were revealed in the flow of

1. The Labrador Inuit Land Claims Agreement created two distinct sorts of jurisdiction for the Nunatsiavut government: the Labrador Inuit goods and information between individuals and households. In so doing, we were guided by three informal hypotheses that are tested here: $\mathrm{H}_{1}$, Inuit living in HVGB will show markedly different social outcomes based on the length of time they have lived there; $\mathrm{H}_{2}$, these social outcomes map onto patterns of intergroup boundaries in HVGB that are discovered in the interview recruitment process; and $\mathrm{H}_{3}$, that both of these outcomes will be better explained by migration patterns after the land claims of 2005-2006 than by the sorts of ethnic/racial exclusion that have been the focus of past research on inequality in the region (Ben-Dor 1977; Kennedy 1982). The third hypothesis was informed by our findings from Nain (Dombrowski et al. 2014). There we discovered that mid-twentieth-century community relocations interacted with current-day economic trends to produce two somewhat distinct but overlapping systems of inequality. Social divisions encountered by relocatees (and their descendants) were based on economic status. For nonrelocatees, social affiliations crossed income lines but did not normally extend to relocatees (or their descendents). $\mathrm{H}_{3}$ is meant to highlight the potential for similar issues in HVGB.

\section{Data and Methodology}

Over the course of 2 years we performed 833 network interviews (330 and 503, respectively, in Nain and HVGB), conducted 10 months of direct/participant observation of community life and public events (between 2010 and 2011), collected more than 20 in-depth informal interviews (including eight photo-voice interviews), and performed more than 400 brief, narrative, open-ended interviews on household movement histories for individuals now living in HVGB. All of the interviews involved a one-on-one question/answer format in a rented project office suite, with data recorded via research software designed specifically for the project. Participants were recruited via a peer-referral strategy described in detail below. The majority of the interviews $(\sim 70 \%)$ were conducted by K. Dombrowski (principal investigator) and J. Moses (coinvestigator), with the remainder collected by a postdoctoral scholar, two graduate students, and two undergraduates. All of the network question/answers were direct coded into the custom database, and narrative answers were outlined by the interviewer into the same database and digitally recorded for detail, backup, and, where necessary, clarification. Ordinary interviews lasted from 20 to 120 minutes (Dombrowski et al. 2013c). The project also employed four part-time Inuit advisors who assisted with recruitment and local liaison functions. The network modeling team was headed by B. Khan (co-principal investigator) and two graduate students. The work

Lands, which is located along the coast and around the five current communities in the region, and the Labrador Inuit Settlement Area, which is much larger but over which the Nunatsiavut government has no direct control, although it shares some management responsibilities (Branch 2005; Natcher and Procter 2012). 
was carried out with the oversight and approval of the $\mathrm{Nu}$ natsiavut Research Committee, and all participants gave informed consent to be interviewed. As described below, participants were compensated monetarily for their time and assistance in project recruitment.

The project employed a participant recruitment method modeled on the "hard-to-reach" sampling strategies of respondentdriven sampling (RDS; see Heckathorn 2002, 2007; Salganik and Heckathorn 2004; Wejnert 2009). Under this framework, researchers start with a handful of paid interviewees called "seeds" who are then given three numbered coupons afterward that can be used to recruit other eligible participants to the project. Successful recruitments are monitored by noting the identification number of the recruiting coupon presented by each new respondent, and recruiters are rewarded with an additional recruitment incentive for each eligible person who appears for an interview with one of his or her recruiting coupons. Each new participant is, in turn, given three recruiting coupons, and the process continues in iterative fashion. Recruitments are limited to three (hence, three coupons), and individuals may be interviewed only once. In both communities, we compensated interview participants with CAN $\$ 30$ and gave a recruitment bonus of CAN\$10 for each successful recruitment. In total, participants could earn a maximum of CAN $\$ 60$ by participating in the project. The sampling results for the research in Nain are discussed elsewhere (Dombrowski et al. 2014).

The advantages of the recruitment method have been noted in other discussions of RDS (Abdul-Quader et al. 2006). Peer recruitment ensures that potential participants hear about the project from a local individual who has herself already participated in the interview and can vouch for the good-faith nature of the research process. It also thus provides a high level of research transparency while simultaneously respecting the privacy of community members who do not wish to participate (by eliminating researcher-led recruitment after the first wave of seeds). In addition, RDS generally results in high numbers of participants in relatively short periods of time, introducing the researchers to the community quickly, easily, and in ways that facilitate later in-depth interviewing and direct observation. Finally, the tracked referrals and related interview data can allow for sampling evaluations and statistical weighting of populations that, to an extent, can be used to correct for the nontraditional sampling frame.

Recently, researchers using RDS have noted that the method also provides an important source of information on the community structure of the population from which the sample is drawn. Following Wejnert (2010), we recognize that the sampling data can be used to uncover features of community connectedness associated with in-group and group-to-group affiliation (and thus disaffiliation or exclusion as well). This analytic strategy has been previously used by the authors in the community of Nain (Dombrowski et al. 2013c). Given the extensive work already published on Nain by the authors, this paper focuses on a similar analysis of HVGB, particularly on the status and integration of Inuit now living there.

According to the 2011 Statistics Canada National Household Survey, HVGB has a population of $7,455,48.7 \%$ of which is male

Table 1. Comparison of raw sample data to 2011 Statistics Canada data

\begin{tabular}{lcc}
\hline Variable & Network survey & 2011 household census \\
\hline Gender: & & $n=7,455$ total population \\
$\quad$ Female & $262(52.1)$ & $3,825(51.3)$ \\
Male & $241(47.9)$ & $3,630(48.7)$ \\
Identity: & $249(49.5)$ & $n=7,455$ total population \\
Inuit & $110(21.9)$ & $2,485(33.3)$ \\
Mixed & $20(4.0)$ & $1,405(18.8)$ \\
First Nation & $124(24.7)$ & $420(5.6)$ \\
$\quad$ Nonaboriginal & & $3,665(49.2)$ \\
Education: & $238(47.3)$ & $n=6,070>15$ years old \\
No high school diploma & $104(20.7)$ & $1,350(22.2)$ \\
High school diploma & $157(31.2)$ & $1,120(18.5)$ \\
Postsecondary & & $3,605(59.4)$ \\
Employment: & $269(53.5)$ & $n=6,070>15$ years old \\
$\quad$ Not in labor force/unemployed & $227(45.1)$ & $1,950(32.1)$ \\
Employed & 472 & $4,125(68.0)$ \\
Mean after-tax income, CAN\$/week & & 711 \\
\hline
\end{tabular}

Note. Data are no. (\%) unless otherwise indicated.

"The term "mixed" requires explanation and clarification. Several terms are amalgamated here, including both "mixed" and "Kablunângajuk" as well as "Métis," "Inuit Métis," and "NunatuKavut." Kablunangajuk was previously a derogatory term (roughly translated locally as "trying to be a white person") that was later used in the Labrador Inuit Land Claims Agreement for descendants of an earlier generation of mixed Inuit and European settler ancestry. While few respondents in our study used the term "Kablunangajuk," several adults used the term "mixed," and some even used "LIA" (short for Labrador Inuit Association, the political organization that brought the original land claim) to describe their background. "Métis," "Inuit Métis," and "NunatuKavut" are all terms that are also used by individuals of mixed descent from the south coast of Labrador who are currently seeking official recognition as a distinct aboriginal group. 
and $50.8 \%$ of which is of aboriginal origins. ${ }^{2}$ Table 1 shows a comparison of the unadjusted RDS sample and the 2011 Statistics Canada National Household Survey results. The HVGB sample overrecruited participants self-identifying as Inuit and underrecruited nonaboriginals. In addition, our raw sample was less educated and contained fewer individuals in full-time employment. Table 2 contains additional sample information from the network interviews for which no official comparisons are available. Mean income was also lower (although there existed a wide range within the sample, which can be seen under "household weekly income" in table 2).

Three factors likely played a role in the observed recruitment bias. The first was that we were paying for interviews, meaning that those with lower income (or no income) would find greater incentive to participate in the research interviews than those with higher income and higher levels of employment. Second, our primary interview hours were during the day, when many full-time-employed individuals were unable to participate. Third, word spread early that our project was intended as a study of Inuit in HVGB, and many non-Inuit folks were surprised to learn that they were eligible to participate. This may have contributed to the oversampling of Inuit.

Overall, however, our sample did reach RDS recruitment equilibrium across nearly every variable (see the appendix, available online). This means that further recruitment was unlikely to significantly alter our sample and that the patterns of referral demonstrated in the recruitment of the sample had reached a steady state. Thus, although the sample is not representative of the community as a whole (in terms of population distribution), the intergroup patterns of relationship discovered in the sample are robust and can form the basis for generalization across the community and in comparison with other RDS samples, such as that from the nearby community of Nain.

For these reasons, we feel that the recruitment method was successful for our purposes. Although sample bias remains a concern, the means for correction weighting can be drawn from both the RDS sampling data and the Statistics Canada data, and the peer referral process allows us to reach a high number of individuals who may have been left out of the official data due to problems associated with sampling individuals with high residential transience (which many more marginal Inuit in the community have). And despite our repeated denials stating that this was not specifically a research project about Inuit in the community, this group remains an important focus of our research and is a population for which

2. Statistics Canada (2013) notes a global nonresponse rate for the community of $37.4 \%$ for the 2011 household survey, indicating a relatively high level of nonparticipation. The round-number figure $(33.3 \%)$ for the number of Inuit in the community likely indicates an even higher level of uncertainty for this subpopulation compared with other, more stably housed subpopulations. Put more directly, 33.3\% sounds a lot like a guess.
Table 2. Additional sample variables and their distribution

\begin{tabular}{lccc}
\hline Variables $^{\mathrm{a}}$ & $N$ & Mean & SD \\
\hline No. of siblings & 499 & 4.49 & 3.0 \\
No. of times married & 494 & .58 & .6 \\
No. of children & 493 & 1.94 & 1.9 \\
No. of residents in current household & 486 & 3.01 & 1.6 \\
Years in community & 490 & 22.6 & 17.1 \\
Years at current residence & 474 & 9.39 & 11.9 \\
Household weekly income, CAN\$/week & 370 & 742.57 & 443.07 \\
Current age & 503 & 41.1 & 15.9 \\
Personal network size & 503 & 22.8 & 34.0 \\
\hline
\end{tabular}

a Other variables not shown: father's place of birth, mother's place of birth, no. of siblings currently living in Happy Valley-Goose Bay, no. of relatives living with you, no. of adults in current residence, no. of children in current residence, no. of parents living with you, no. of bedrooms in residence, no. of domestic violence victims known, boat access, cabin access, and skidoo access.

no conventional sampling method is available. As will be seen below, the high number of referrals (393 in all) represents a large database from which to draw inferences about where and why community boundaries exist. These data, we feel, compensate considerably for the uncertainties introduced in subsequent weighting estimations. ${ }^{3}$

The primary concern of this paper is to better understand how Inuit who have left the coastal communities of Nunatsiavut differed, if at all, from more long-term Inuit residents in HVGB and whether these differences could be mapped to differences in social connectedness. Table 3 shows data for various subgroups within the sample. Here it is easy to see that Inuit fare worse than nonaboriginal folks in HVGB, but these findings mask important differences within the Inuit subpopulation. Of the 249 self-identified Inuit interviewed, 70\% had been born on the coast, and just under $20 \%$ had moved to HVGB from a coastal community since the institution of the land claims agreement. Inuit who were born in HVGB displayed higher average income, better employment statuses, and more access to tools needed for subsistence food gathering than those who were born on the coast. In turn, those who were born on the coast but moved before the land claims settlement did better in all three measures than those who moved from the coast after the land claims settlement. Interestingly, the only category on which migration history seems to have little impact is in the overall level of education of individuals in that group, the means of which are very similar across all groups and subgroups.

To examine the recruitment data for bias, RDS analysis normally measures "homophily/heterophily." In ordinary terms,

3. Because our main interest in the initial portion of the paper is a comparison of subgroups (rather than a characterization of the community as a whole), unweighted statistics are presented in tables 1-3. In tables 4-6, weighted statistics are used in the calculation of homophily and affiliation measures as encoded in the RDSAT software and procedures (Spiller, Cameron, and Heckathorn 2012). 
Table 3. Subpopulations in Happy Valley-Goose Bay (HVGB)

\begin{tabular}{|c|c|c|c|c|c|c|c|}
\hline Population & $\begin{array}{l}\text { No. of } \\
\text { respondents }\end{array}$ & $\begin{array}{c}\text { Individual } \\
\text { weekly income, } \\
\text { CAN\$/week }\end{array}$ & $\begin{array}{l}\text { Household } \\
\text { weekly income, } \\
\text { CAN\$/week }\end{array}$ & $\begin{array}{l}\text { Employment }^{\mathrm{a}} \\
\text { (scale, 0-4) }\end{array}$ & $\begin{array}{l}\text { Subsistence } \\
\text { (scale, 0-6) }\end{array}$ & $\begin{array}{l}\text { Education }^{c} \\
\text { (scale, 1-5) }\end{array}$ & $\begin{array}{l}\text { Mean (SD) net } \\
\text { size (people) }\end{array}$ \\
\hline All respondents & 503 & 472 & 743 & 1.57 & 2.36 & 2.89 & $22.79(34.0)$ \\
\hline Nonaboriginal & 124 & 551 & 809 & 1.19 & 2.49 & 3.40 & $22.75(26.8)$ \\
\hline All Inuit in HVGB & 249 & 406 & 659 & 1.27 & 2.04 & 2.75 & $20.50(32.6)$ \\
\hline Inuit born in $\mathrm{HVGB}$ & 121 & 499 & 793 & 1.83 & 2.8 & 2.89 & $21.95(36.0)$ \\
\hline Born on the coast & 130 & 328 & 529 & .74 & 1.25 & 2.59 & $19.1(29.3)$ \\
\hline $\begin{array}{l}\text { Born on the coast } \\
\text { and left since } 2005\end{array}$ & 45 & 235 & 373 & 62 & 98 & 268 & $12.04(9.5)$ \\
\hline
\end{tabular}

${ }^{a}$ Employment scale: unemployed (0), occasional (1), seasonal (2), part time (3), and full time (4).

${ }^{\mathrm{b}}$ Subsistence access is a composite factor. Each respondent was asked if they owned (2) or had reliable access to (1) each of the three most important subsistence tools: a skidoo, a boat, and a cabin in the country. For an individual who owned all three, the composite score would be 6; for someone with no reliable access to any of the three, the score would be 0 .

${ }^{c}$ Education was scaled as follows: no high school (1), some high school (2), finished high school (3), some college/trade school (4), and completed college/trade school (5).

this is the tendency of individuals in a particular group, identity, or status to associate with individuals within (homophily) or outside (heterophily) their own group, however that group is defined, at levels greater than one might expect from a random mixing of individuals. Thus, if women in a population tend to associate with greater than random frequency with other women, then we would describe the situation as characterized by gender homophily with respect to women. Heterophily is the opposite, for example, a situation where women tended to affiliate primarily across gender rather than within.

In RDS analysis, tendencies toward homophily or heterophily are measured on a scale of -1 (perfect heterophily) to 1 (perfect homophily), with 0 indicating attribute neutrality, which we might expect from random mixing. In general, few groups practice absolute tendencies of homophily or heterophily in any social context. Instead, we normally find a graded measure somewhere between the two, indicating low, moderate, or high levels of inward-/outward-looking affiliation from individuals in one group/category toward those in their own or other groups. Heckathorn, the original developer of the method, notes that homophily/heterophily levels between -0.3 and 0.3 indicate low levels of out-group/ingroup preference (Heckathorn 2002). ${ }^{4}$ Levels above this indicate important patterns in affiliation/disaffiliation between groups in the community.

4. Among the more difficult problems in determining homophily is separating degree homophily $\left(H_{\mathrm{d}}\right)$ from attribute homophily $\left(H_{\mathrm{a}}\right)$. The former is found when one group has a higher overall average number of connections than another. Here a random assortment of ties that fit the degree distribution of all parties would necessarily result in more ties within the group with the larger network size than between groups, despite no actual preference for in-group ties. The separation of degree homophily influences from homophily associated with actual preference for in-group affiliation is discussed by Wejnert et al. (2008) and is incorporated in the $H_{\mathrm{x}}$ calculations of RDSAT (Spiller, Cameron, and Heckathorn 2012).
Patterns of homophily/heterophily normally affect recruitment, and considerable attention has been paid to their estimation and correction (Berchenko, Rosenblatt, and Frost 2013; Gile and Handcock 2010; Goel and Salganik 2009, 2010; Mouw and Verdery 2012). This weighted correction process is taken into account in the estimation tables below, but other insights can be gained from these same data. More specifically, conventional RDS analysis has used homophily estimation to help produce sample weighting for correction purposes. Wejnert (2010) has recently pointed out that these same measures can also inform researchers on the presence and absence of structural features of the social network from which they are drawn. In this analysis, we follow Wejnert and examine the homophily/heterophily levels associated with particular groupings and, where high levels exist, interpret this as a lack of social interaction, trust, and affiliation between members of those groups (see also Dombrowski et al. $2013 c, 2014)$. In the process, we describe a means for understanding the social isolation/nonisolation of groups vis-àvis other groups in the same community. This effort represents a methodological step toward discovering and measuring (in relative terms) long-standing anthropological concerns with ethnic boundary marking/making and structures of internal inequality but expands it beyond identity into other areas (such as income) or less visible and less conscious boundary markers like the combination of historical events and current local group affiliation. The literature on ethnic boundaries and their subtlety is large (for an interesting review, see Steward 2013; for a view beyond anthropology, see Wimmer 2013). We note, however, that the methods used to understand these processes remain divided into those that rely on local understandings/models of those boundaries (as in most ethnographic work) and those that associate boundaries with measureable differences in group outcomes (as in most sociological work). Few means have been employed to attempt to "see" boundaries in action. Here we use the passing of the referral coupons as an experiment in boundary discovery. The method, then, is to look 
at deviations from the random affiliation (of nearly 400 referral events) as a kind of social topology that contains information on the contour lines of social affiliation. Although novel and more statistically complex, it is easy to see such an approach as rooted in an earlier anthropological engagement with exchange theory (for a classic appraisal, see Befu 1977; for social network revitalization of this area, see Cook et al. 2013).

A network approach to boundary making/marking such as that proposed here is far from foolproof, but it can provoke worthwhile questions for additional, in-depth ethnographic analysis. Furthermore, because the measures of group interaction are drawn from a wide sample of connections and interviews (i.e., from hundreds of recruitments that take place outside the view and influence of the researcher), the results are largely impervious to researcher and respondent preconceptions of the social forces at work in grouping and dividing the community. This creates the potential for surprise and new information when discovered patterns contrast with existing interpretations of exchange and affiliation by participants and/ or researchers.

And finally, the statistical analysis of the recruitment data allows researchers to investigate the interaction of distinct affiliation modes. The latter is something that is otherwise difficult to measure and as such frequently goes unobserved (and thus unreported) in interview settings. Thus, for example, one can analyze the referral and recruitment data to investigate the interaction of gender exclusion and income differentials in rendering some groups more or less socially isolated than others. Normally this kind of "intersectionality" can be inferred only from the sorts of outcomes they seek to explain, a highly problematic sort of reasoning (according to this logic, we assert marginality on the basis of differentiated outcomes when in fact it is these very outcomes we seek to explain). In the method employed here, outcomes such as social isolation and economic marginality are measured via analysis of the social connections among those participating in the interview, and their combined effects can be seen in the patterns that emerge from the recruitment networks. The patterns that describe these connections are not visible except from the macroscopic view of the whole sample and often reveal patterns of interconnection (and nonconnection) not visible to those involved. To our mind, this represents a considerable step forward in our attempt to discover and explain the relationship between social boundaries and social outcomes such as employment, access to traditional foods, and housing status (Dombrowski et al. 2013b).

\section{Results}

In the tables below, within- and between-group affiliations will follow set conventions (see fig. 1). Each row in a table will show the affiliation of the group in the first row to the group shown in each subsequent column. In those cases where the row and column names are the same, the value will indicate the tendency of members of the group to affiliate with one another

\begin{tabular}{c|c|c} 
Group & $X$ & $Y$ \\
\hline$X$ & $X \rightarrow X$ & $X \rightarrow Y$ \\
\hline$Y$ & $Y \rightarrow X$ & $Y \rightarrow X$
\end{tabular}

Figure 1. Interpretation of affiliation tables.

(i.e., homophily). Where the row and column names differ, the value will indicate the tendency of those in the row to affiliate with those in the column (i.e., heterophily). We note that this matrix need not be symmetrical where we have more than two groups. This idea, like several of the ideas presented here, makes intuitive sense (there is no reason that members of group A will prefer to affiliate with group B to the same extent that group B will prefer to affiliate with group A) but has received little attention in anthropology. As we have argued elsewhere, such asymmetric social boundaries are among the more interesting potential findings from the sort of analysis proposed here (Dombrowski 2007, 2014).

Below are a series of affiliation matrices (tables 4-8) showing the homophily/heterophily of the sample from the HVGB on the basis of ethnic identity, place of birth, and income. As above, we interpret homophily/heterophily scores of more than 0.3 as indicating moderate to high levels of in-group/between-group affiliation and scores of less than -0.3 as indicating moderate to high levels of in-group/between-group disaffiliation or avoidance. Scores indicating moderate to high levels of either affiliation or disaffiliation are underlined in the tables. We note, however, that the extent to which moderate to high levels of either affiliation or disaffiliation indicate a pattern of social exclusion cannot be gained simply from the raw scores alone but must also be drawn from the ethnographic data that accompanied the referral process. This issue is taken up in the discussion below.

\section{Ethnic Identity}

Table 4 shows the results of an affiliation matrix based on the self-identified ethnic identity of study participants in HVGB. Overall we see high levels of homophily and disaffiliation by ethnic identity across most groups: as seen in row 1, Inuit show a moderate level of homophily (0.317) and moderate levels of disaffiliation with those identifying as other aboriginal ( -0.466 ; primarily Labrador Innu) and nonaboriginal $(-0.323)$ and low to moderate levels of disaffiliation with mixed $(-0.253)$. This disaffiliation is reciprocated with moderate to high levels of disaffiliation from all groups to Inuit, as seen in column 1 . Similarly, other aboriginal-identified individuals (row 2) show a moderate level of homophily $(0.343)$ and disaffiliation with Inuit $(-0.392)$ and nonaboriginals $(-0.589)$ - a pattern that is reciprocated in the nonaboriginal-to-other aboriginal score $(-0.692)$. 
Table 4. Affiliation matrix by ethnic identity

\begin{tabular}{lcccc}
\hline Population & Inuit & $\begin{array}{c}\text { Other } \\
\text { aboriginal }\end{array}$ & Mixed & Nonaboriginal \\
\hline Inuit & $\underline{.317}$ & $\underline{-.466}$ & -.253 & $\underline{-.349}$ \\
Other aboriginal & $\underline{-.392}$ & $\underline{.345}$ & .003 & $\underline{-.589}$ \\
Mixed & $\underline{-.352}$ & -.23 & .252 & .005 \\
Nonaboriginal & $\underline{-.445}$ & $\underline{-.692}$ & .0 & $\underline{.343}$ \\
\hline
\end{tabular}

Note. For all affiliation tables (tables 4-8), dual-component analysis (using the enhanced data-smoothing algorithm) with 10,000 bootstrap resamplings was employed in RDSAT 7.1.38. Confidence interval $\alpha$ was set to 0.025 (for a $95 \%$ confidence interval), and self-estimated network size outliers of the top 5\% were "pulled in" (Spiller, Cameron, and Heckathorn 2012). Seeds were excluded from the analysis. Scores indicating moderate to high levels of either affiliation or disaffiliation are underlined.

Throughout, table 4 shows what might be expected to those familiar with patterns of ethnic boundaries in Labrador: significant social barriers between nonaboriginals and Inuit/other aboriginals (see, e.g., Kennedy 1982; Sider 2014; Taylor 1979). Of note as well: the mixed group shows neither strong patterns of affiliation nor disaffiliation with the other categories, placing them in something of a middle ground. In general, were we to look only at this table, we would find a complex picture of integration by ethnic identity with aboriginal groups quite isolated from nonaboriginals, and Métis/mixed groups forming something of a middle ground. Our argument, however, is that this view masks significant divisions based on whether those self-identifying as Inuit were born on the coast or not (and especially whether those born on the coast had migrated since the land claims settlement). To examine this possibility, several additional analyses of the recruitment data were undertaken that focused on place of birth rather than ethnic identity.

\section{Place of Birth}

To test our hypotheses on social boundedness of coast-born individuals now living in HVGB, we examined the homophily and affiliation levels for the sample based on the RDS recruitment patterns using place of birth as the clustering criteria (see table 5). As seen there, we found evidence of moderate homophily (self-affiliation) for those born in the five communities along the Labrador coast that make up Nunatsiavut (0.404). As interesting, however, is the extent to which disaffiliation is apparent in the relationship from coast-born individuals to those born outside Labrador $(-0.723)$. These are very extreme values, indicating considerable social closure and even greater levels of out-group avoidance. The only nonextreme value is the interaction levels between coast-born individuals and those born elsewhere in Labrador. This value is also negative $(-0.264)$, showing a tendency toward disaffiliation/avoidance but not to the extent discovered for other groups.

Looking at the subsequent rows, the disassociation is reciprocated by both of the other groups at similar or larger levels. The other-to-coast (row 3) values show equally high levels of avoidance of those born on the coast $(-0.77)$. And as importantly, the Labrador-to-coast value shows a much greater level of disassociation $(-0.444)$ than does the coast-toLabrador level $(-0.264)$ seen in row 1 . This would indicate a much more significant social boundary between those born in Labrador (but not on the coast) and those born on the coast than is perceived by the latter. All of these values are even more dramatic compared with the association patterns among non-coast-born Labradorians and those born outside Labrador. All of these values are low but positive, indicating a small but positive tendency to associate with one another. Clearly, those born on the coast in HVGB live with a very high degree of social isolation that is unique to them.

Although clearer than the picture painted by ethnic identity, table 5 does not address the question of out-migration since the land claims settlement, the implications of which are hinted at in table 1. Furthermore, the results in table 5 can potentially be read as a gloss on ethnic identity, with coast-born individuals taking the place of Inuit, and those born in Labrador but not on the north coast being near equivalents to those labeled Métis in table 4. To further examine the effects of the land claims agreement on the patterns of social inclusion shown in tables 4 and 5, we repeated the analysis of the recruitment data while treating migrants who arrived from coastal communities since 2005 as a distinct category.

The results present an important modification of the findings shown above. When those who were born on the coast and subsequently migrated after 2005 are treated separately in the analysis, they show similar levels of isolation as those who were born on the coast and migrated earlier. But where one might expect some marked positive affiliation between these two groups, the pattern is actually neutral. Both groups show some homophily, but their affiliation levels are not much above what we would expect from a random mixing scenario.

Ethnic identity in this region has, for many years, been subsumed within local political structures and land claims processes. One result of this is that ethnic self-identification in Labrador is at least in part a strategic statement, meant to make forward-looking claims on inclusion, political spoils, or even just simple survival in the emerging political landscape. To note this is not to dismiss identity as purely political or opportunistic (as Kuper [1988] does; see also Widdowson and Howard 2008). Such an approach is unnecessarily cynical and misinformed. Rather, the middle ground we seek here is a better understanding of the actual social processes of inclusion

Table 5. Affiliation matrix by place of birth

\begin{tabular}{lccc}
\hline Population & Coast & Labrador & Other \\
\hline Coast & $\underline{.404}$ & -.264 & -.723 \\
Labrador & $\underline{-.444}$ & .239 & .025 \\
Other & $\underline{-.77}$ & .178 & .204 \\
\hline
\end{tabular}


Table 6. Affiliation matrix by place of birth (recent migrants separate)

\begin{tabular}{lcccr}
\hline Population & Since 2005 & Coast & Labrador & Other \\
\hline Since 2005 & .195 & .091 & -.264 & $\underline{-.64}$ \\
Coast & .017 &. .363 & -.259 & $\underline{-.741}$ \\
Labrador & $\underline{-.33}$ & $\underline{-.45}$ & .236 & .025 \\
Other & $\underline{-.64}$ & $\underline{-.789}$ & .178 & .205 \\
\hline
\end{tabular}

in their interaction with larger political processes, such as land claims and the industrial resource development that follows. Toward this end, a focus on place of birth is potentially able to look at patterns of in-group affiliation that may not fit with the larger political discourse and may not be recognized by those involved. These results and their implications will be discussed in more detail in a later section of this paper.

\section{Income}

Income may play a role in determining social boundaries in HVGB by itself and in conjunction with other variables. The results for individual and household incomes in single variable analyses are shown in table 7 . Here income is measured in two categories, divided at the respective means (see table 1). The table shows low levels of affiliation based on individual income and modest levels of homophily (and out-group disaffiliation) for higher-income households. In comparison with tables 4-6, however, the levels of affiliation/disaffiliation shown here are low, indicating that, on its own, income differences produce lower barriers to social interaction than either place of birth or ethnic affiliation. Were we to look at this table alone, we might conclude that income plays little role in levels of affiliation/ disaffiliation in the community.

To further investigate whether economic status does and does not affect affiliation, we performed a multivariate analysis of these same data based on household income, which showed the higher level of social differentiation (again, dichotomized at the mean) and both ethnic identity (Inuit/non-Inuit) and place of birth (born on the coast/not born on the coast). These results are presented in table 8 . Here we see an interesting mixing of forms of social separation. Overall, affiliation by place of birth turns out to be far more stratified and significant than affiliation by ethnic identity, with high levels of homophily shown by several groups and significant disaffiliation between those born on the coast and those born elsewhere. However, unlike those born elsewhere, those born on the coast show a tendency to cluster by income; both income groups show levels of homophily greater than 0.3 .

When we examine the timing of those moving away from the coast and look only at those who have left since the land claims of 2005-2006, the pattern is stark. Although there are too few exchanges across income and the since-2005 group to draw statistical conclusions, we note that only one referral took place across income levels within the since-2005 group. Rather, the mixing pattern was largely random between those born elsewhere and the since-2005 group. Overall, income seemed to play little role in the patterns of affiliation between these groups. These conclusions lack the statistical confidence of the other tests shown above, but we note that these findings provide preliminary evidence that those leaving the coast since the land claims are not only the most economically marginal but are also among the most socially isolated. We also note that what evidence we do have points to the idea that this group shows markedly different patterns of social interaction from both the Inuit more broadly and those who migrated before the land claims settlement.

\section{Discussion}

Three informal hypotheses were raised for analysis above. The first $\left(\mathrm{H}_{1}\right)$ of these - that the social outcomes of Inuit in HVGB will reflect the length of time they have lived there (with those arriving after the land claims settlement showing the poorest outcomes) - is borne out in table 3. Those migrating from the coast since 2005 show considerably lower incomes, employment levels, and access to subsistence resources compared with all other groups in HVGB, despite comparable overall levels of educational achievement.

Evidence for the second hypothesis $\left(\mathrm{H}_{2}\right)$ - that social outcomes would map onto patterns of intergroup affiliation and disaffiliation - can be found in tables 5 and 6 . Here individuals born on the coast show a high level of in-group affiliation

Table 7. Affiliation matrix by income (dichotomized at mean)

\begin{tabular}{|c|c|c|}
\hline & Under CAN $\$ 472 /$ week & Over CAN\$472/week \\
\hline \multicolumn{3}{|l|}{ Individual income (after tax): } \\
\hline Under CAN\$472/week & .029 & -.029 \\
\hline \multirow[t]{2}{*}{ Over CAN\$472/week } & -.202 & .202 \\
\hline & Under CAN\$711/week & Over CAN\$711/week \\
\hline \multicolumn{3}{|c|}{ Household income (after tax): } \\
\hline Under CAN\$711/week & .252 & -.252 \\
\hline Over CAN\$711/week & -.379 & .379 \\
\hline
\end{tabular}


Table 8. Multivariate affiliation table of household income

\begin{tabular}{|c|c|c|c|c|}
\hline & Inuit/low income & Inuit/high income & Non-Inuit/low income & Non-Inuit/high income \\
\hline \multicolumn{5}{|c|}{ Ethnic identity and household income: } \\
\hline Inuit/low income & .395 & .004 & -.366 & $\underline{-.743}$ \\
\hline Inuit/high income & -.213 & .214 & -.289 & -.144 \\
\hline Non-Inuit/low income & -.489 & -.262 & .216 & .028 \\
\hline \multirow[t]{2}{*}{ Non-Inuit/high income } & $\overline{-.81}$ & -.183 & -.011 & .34 \\
\hline & $\begin{array}{l}\text { Coast-born, lower } \\
\text { income }\end{array}$ & $\begin{array}{l}\text { Coast-born, higher } \\
\text { income }\end{array}$ & $\begin{array}{l}\text { Non-coast-born, lower } \\
\text { income }\end{array}$ & $\begin{array}{l}\text { Non-coast-born, higher } \\
\text { income }\end{array}$ \\
\hline \multicolumn{5}{|l|}{ Place of birth and household income: } \\
\hline Coast-born, lower income & .345 & .03 & -.067 & -.777 \\
\hline Coast-born, higher income & .004 & .352 & -.41 & -.447 \\
\hline Non-coast-born, lower income & -.319 &.$- \overline{482}$ & $\overline{.191}$ & $\overline{-.049}$ \\
\hline Non-coast-born, higher income & -.856 & -.57 & -.159 & .408 \\
\hline
\end{tabular}

and higher levels of isolation from those born elsewhere. Table 6 provides further evidence of social isolation of those born on the coast who migrated only recently, with the latter showing marked patterns of social isolation vis-à-vis noncoast groups and neutral sorts of affiliation with others from the coast. Overall, analyses involving place of birth, as opposed to ethnic identity, show more distinct, stark, and clear lines of social difference. As above, we interpret these results to imply that economic and ethnic considerations alone (table 8) are not sufficient to understand the levels of disaffiliation encountered by some groups. When the results shown in table 6 are combined with the data in table 3 , it is clear that those born on the coast who migrated since the land claims are among the most socially isolated as well as the most economically marginal.

Finally, we hypothesized $\left(\mathrm{H}_{3}\right)$ that economic factors would mix with migration since the Labrador Inuit Land Claims Agreement of 2005-2006 to further exacerbate the isolation of this group. This hypothesis finds mixed support. In table 8 we find considerable difference between those born on the coast and those born elsewhere, as place of birth (more than ethnic identity) combines with economic differences to draw clear lines of social boundedness. Those who left the coast since 2005 and who live in households with low income show high levels of social isolation, though as above these results lack the same statistical confidence levels as the data shown in table 8 .

Together, these results point to a phenomenon that often remains hidden in our discussion of indigenous land claims: namely, that economic conditions in communities at the center of successful land claims can change significantly and for the worse for those on the community's social margins despite the new opportunities created by economic development and selfgovernment. They also witness new forms of migration for those with greater financial means. The rate at which this happens may be hidden behind the growth of successful land claims communities. Between 2006 and 2011 Nain grew by 154 people, according to Statistics Canada. One has to look closely at these same figures, however, to discover that 115 people (nearly $10 \%$ of the total population) moved into the community in the past 5 years and that there were $\sim 125$ children born to Nain families during this time. Thus, with 115 new entries and 125 births, the 154 person gain in population masks an out-migration of 86 persons during this same time period.

Interviews with former coast residents who had recently migrated to HVGB help to explain the causes of this process. While few cited the land claims agreement directly, the discussions of those who left coastal communities since the land claims settlement in 2005 fell into two categories, which map well onto the divisions suggested in table 8 . For those with higher income, their recent relocation took place as a response to job and educational opportunities available outside the small coastal villages. For those on the economic margins, migration tended to take place in response to deteriorating personal economic conditions and an intensification of social problems they felt were unavoidable in their home communities. Whether and to what extent this process leads to a split between those pursuing a heroic (and cosmopolitan) "indigenous life project," in the words of Australian theorists Cowlishaw and Lea (2010), and those tossed willy-nilly into what Paul Collier (2008) refers to as the "bottom billion" remains an open question.

The ways in which social interaction and social boundaries have been reconfigured in Labrador points to the manner in which the current situation differs from those reported by anthropologists in past research in Labrador. Where Ben-Dor (1977) foresaw the eventual absorption of Inuit into what he called "settler" culture/community, particularly as "mixed" children in Makkovik tended to affiliate more closely with their non-Inuit kin over time, and where Kennedy (1982) saw the likelihood of sustained ethnic isolation with Inuit on one side and settlers on the other, the current data reveal a situation where Inuit identity has been attached to a political process, that is, land claims and ongoing industrial resource develop- 
ment. As this process advances, sources of social exclusion do not, however, disappear. Rather, it would appear that they are repackaged under different, perhaps unspoken or unnamed social categories. Thus, in Labrador the social boundaries witnessed by Ben-Dor and Kennedy remain, though not in a form that either researcher would likely recognize. An alternative understanding to this process of gradual acculturation and assimilation can be found early on in Paine (1977) and more recently in work by Sider (2014). There the historical contingency of the organizing categories used in Labrador (and beyond) are called into question, and the social and individual chaos that this created is seen as directly leading to the type of outcomes that many relocatees cite as reasons for leaving.

Here we can speculate on this as a more general process across the indigenous world. As above, Canada, like the United States and Australia, now requires a very narrow version for indigenous self-assertion to satisfy land claims requirements and gain official recognition, one that links state recognition of claims to industrial resource development. In the process, local organizations become quasi-state entities, brokering indigenous identity and access, while acting where and in ways the Canadian state often could not. Increasingly, the state's role in organizing the process is largely effaced though a series of standardized "impact benefit agreements" (Dombrowski 2008). The result is a highly capitalist version of what Tania Li has called the "tribal slot" (Li 2000, 2014).

Of course, not all indigenous land claims are caught up with industrial development. Where few resources might be had, we need to look to other explanations, including a hegemonic welfare state apparatus (Austin-Broos 2011; Lea 2008). Among the more visible but frequently unmentioned repercussions of both of these land claims processes are the waves of "culturally necessary victims," as Hermann Rebel (1989) once put it, who move out of successful land claims areas and, as such, seemingly out of ethnographic view (Cowlishaw 2009). On their own, these victims are often marginal and at times ghostly figures of many northern, nonaboriginal towns. As a group, however, they are a sign of a larger process of reorganization ongoing in the relationship between state and capital in the Arctic. This process, which began in the early 1970s but accelerated quickly after the end of the Cold War, has seen the swift demilitarization of the North and a rapid opening of much of the Arctic to industrial development. In the process, the relationship between governments and the industries of development has been continuously drawn and redrawn. This flux is seldom raised in current discussions of culture change, despite appearing on the front page of many newspapers in the form of environmental concerns, labor inclusiveness, or the specter of aboriginal suicide. Rather, capital and state are normally treated as a single external monolith. Yet land claims movements have provided state and capital with myriad ways to reconstruct advantageous relationships in the North under a banner of indigenous rights and sovereignty. Like its largely silent harbingers - the raft of new migrants found on the margins of Iqaluit, Goose Bay, Yellow Knife, and Anchorage, or further away in Sydney - the ongoing parry and post of industrial resource development via indigenous land claims remains largely invisible. For anthropologists of indigenous communities, this matters because the communities we work in have become, in effect, the grease that allows this constant negotiation to take place, and to take place in plain sight of otherwise skeptical publics. This is true whether anthropologists tend to view this process of community transformation as creative revival (Clifford 2013), crude opportunism (Widdowson and Howard 2008), or the fault of "liberal allies" (Sutton 2011). There are, of course, elements of all of these in the process, though too little attention is paid to the particular constraints on cultural production produced as part of this rapidly changing milieu. Despite an uptick in historical contextualization (Austin-Broos 2011) and some signs of renewal (Clifford 2013), views that place both indigenous communities' choice of struggles and our own choice of ethnographic objects in the context of contemporary global processes remain too few.

\section{Acknowledgments}

This project was supported by a grant from the Division of Arctic Social Sciences, Office of Polar Programs, US National Science Foundation (GR ARC 0908155), with the approval of the Nunatsiavut Research Committee. All of the material contained here was obtained with the informed consent of all participants. Analysis of the data and all conclusions and recommendations are the responsibility of the principal investigator/lead author and do not represent the opinions of either the US National Science Foundation, the Nunatsiavut government, the Nunatsiavut Research Committee, or the University of Nebraska-Lincoln. Special thanks are due to Fran Williams, Jane Dicker, Toby Pijogge, and Eva Lampe.

\section{Comments}

\section{Dmitry V. Arzyutov}

Department of Anthropology, School of Social Sciences, University of Aberdeen, Edward Wright Building, Aberdeen AB24 3QY, United Kingdom (d.arzyutov@abdn.ac.uk), and Department of Siberian Ethnography, Peter the Great Museum of Anthropology and Ethnography (Kunstkamera), St. Petersburg, Russia. 6 IV 16

As the authors of the article based on social network analysis argue, the relations between community relocation experiences and aboriginal land claims movements in Labrador are deeply interlinked. Relying on the fascinating data arranged by scientific methods leaves almost no room for critics. In my comment, I venture to bring some Siberian examples to the general discussion of relocations and land claims in 
the Arctic and try to correlate them with the hypotheses of the authors. I must say, such social network analysis and response-driven sampling have never been conducted in Siberia, but I am sure the results of such analysis would be very fruitful.

Across all of the Russian Arctic and other parts of Russia, there has been a chain of relocations of indigenous populations - forced migrations (pereselenie), collectivization (kollektivizatsiia), village amalgamation (ukrupnenie syol)—resulting from different purposes of late imperial (Pallot 1999) and Soviet (see Krupnik and Chlenov 2007; Holzlehner 2011) local and state authorities as well as post-Soviet extraction companies today (Novikova 2014). Most of them expressed the obsessional bureaucratic debates on sedentarization (osedanie) of nomadic peoples as a development project and the idea of progress. Paradoxically, being suspicious of the nomadic life of indigenous people, the state itself became a nomadic one, relocating whole groups as chess pieces. However, indigenous peoples were not the only victims of those forced relocations; many rural communities across the territory of the former Soviet Union were as well.

In my reply I will focus mainly on my Yamal field experience, and the examples will be about forced relocations of nomads instead of village relocations in other parts of the Arctic.

The collectivization and Soviet economic policy resulted in the indigenous protest in northern Yamal known as Mandalada, which was stifled in blood (Golovnev 1995:183-196; Laptander 2014). A few years later, in 1947, there was the massive Yamal relocation of Nenets households from the northern to the middle part of the peninsula due to the fear of a new wave of uprisings and alleged economic development by the Soviets (Lezova 2001). The idea of the forced involvement of indigenous nomads in the state infrastructure thanks to their settling near villages collapsed: Nenets herdsmen preferred to escape the infrastructure and returned to the northern tundra, that is, they marginalized themselves (from the state point of view) for the sake of their safety and the support of reindeer herds. Today, the memory of relocation is still alive among tundra Nenets and shapes their historical identity, their narratives, and their sense of belonging. And along with genealogical transmission of oral histories, this event has been supported by a genealogical representation of reindeer herds, the cores of which are often determined as offspring of "before-therelocation" reindeer. Probably as a result of that experience, northern Nenets like to tell stories about the difference between reindeer from different parts of Yamal, their behavior, and physical features. This Nenets story, in comparison with Inuit relocation, helps us to see relocation in a much broader context of human-animal-landscape interactions as a neglected side of land claims.

If Inuit left the land claims area for the nearby local city of Happy Valley as a predominantly nonindigenous community, the "urbanization" of indigenous people in northern Siberia and the Russian Far East in most cases was not forced in spite of the "villagization" of tundra/taiga life that was a result of church or Soviet sedentarization politics. The names of Yamal village streets, like in Se-Yakha, remember the places where their inhabitants came from.

Most indigenous people in the villages and in the cities strongly support the relations with their tundra or taiga relatives. It means the exchange of goods, hosting, sending children to the tundra for summer vacation, and so on (ArgounovaLow 2007). Both political activists and ordinary people do this (Balzer 2016). These relations are mirrored in the land claims movement, which is known as the obschina movement in Russia (Fohdahl and Poelzer 2003; Fondahl et al. 2001), and in the Yamal context connects land and social (kinship) relations of tundra people (Stammler 2005:252-280). But usually the obschina leaders in Yamal live in the villages or in the cities and visit their relatives (and coworkers) in the tundra. Arctic villages are controversial places in the dialogue between tundra nomads and rural dwellers. Usually for tundra people, the village way of life means the loss of "Nenetsness" and being away from reindeer, while for villagers the tundra is a backward place. The obschina movement reconciles these extremes through the shuttle position of leaders. This analysis shows a difference with the Inuit story presented in the article, but this difference is not so radical since in the cities, like the nonindigenous Yamal capital Salekhard, indigenous people are quite isolated from economic life, being involved only in indigenous and culture politics. In this particular context we can see social boundedness rather than integration of indigenous people into city life. It is partly the result of the politics of forced migrations and sedentarization of reindeer nomads in the Russian Arctic being close to the Inuit example. ${ }^{5}$

\section{Diane Austin-Broos}

Department of Anthropology, University of Sydney, R. C. Mills Building A26, Sydney, New South Wales 2006, Australia (diane.austin-broos@sydney.edu.au).27 III 16

The politics between indigenous minorities and states perforce have been mainly a cultural politics. In this context, it is understandable that successful land claims are often taken as an end point of political struggle involving, as they do, issues of autonomy, sovereignty, and self-determination. "Relocation Redux" notes nonetheless that in the relations between capital, the state, and an indigenous minority - in this case, the Inuit of the Labrador coast-successful land claims involve as often transformations of enduring inequalities.

5. This comment was written thanks to the support of two research projects (ERC AdG295458 and ESRC ES/K006428/1; principal investigator, David G. Anderson). 
"Even as traditional subsistence and land-based practices lay the groundwork for . . claims . . . natural resource extraction [and its social and environmental impacts] degrades ... those lifestyles and livelihoods." This pairing of land claim and resource development brings pressure to commodify land, knowledge, things, and persons, which fosters, in turn, new forms of internal differentiation and stratification.

An account of this dynamic frames a comparison of Inuit relocations: the voluntary and initially enthusiastic ones precipitated by the land claims era, and previous mid-twentiethcentury forced relocations. Though the former were intended to right the injustice of the latter, both were followed by outmigrations from coastal villages to the regional center (HVGB). The authors' comparison underlines the increasing groupspecific "homophily" and immiseration among those marginalized Inuit who migrated in the land claims era, after 2005. Despite opportunities in land claims communities, economic conditions for those at the margin can deteriorate rapidly. The "silent out-migration" that follows, often overlooked in ethnographies of homelands, is also part of a land claims milieu.

Let me bring some comparisons, and contrasts, from an Australianist perspective. Peterson (1986) compares aspects of land rights regimes in Australia, Canada, and the United States. He notes that in the period 1971-1976 all three societies forged major land settlements with indigenous peoples at a time when there was an "explosion of activity" among transnational mining companies (Peterson 1986:95). Each state recognized an equity issue and dealt with it according to a particular conjuncture. Canada and the United States sought to either modify or extinguish (in the longer term) already-acknowledged rights. The Australian state, with no prior legal recognition of an indigenous entitlement, did so by statute in 1976 - for its Northern Territory at least (Peterson 1986:97). Peterson argues that this measure was more than an antiracist redress brought by national and international (UN) pressure. The Australian legislation was also expedient. In central and northern Australia, indigenous people had come late (circa the 1960s) to the cash economy and within a welfare state. After 1968, social service benefits alleviated the need for paid employment among those who lived remote. Whether this "independent income," as Peterson terms benefits, was accepted voluntarily or not, it slowed the inclusion of indigenous people in a world of commodities and cash transactions. The "disengagement from employment" and continuing economy of "limited good" brought a marked estrangement, if not independence, from nonindigenous society (Peterson 1986:93-96; Austin-Broos 2006). Historically, this circumstance was shaped by the absence of the frontier histories of indigenous/nonindigenous trade common in North America. Faced with estranged individuals, opaque kinship units, and outdated settlement social structures, Northern Territory land rights legislation defined legal entities with which capital and state could transact the business of development and welfare policy.
This account underlines the point that capital and state articulate, not merely frame, local socialities and histories. In addition, the cultural politics between indigenous people and capital and state is a racialized one, but also economic and environmental.

There is commonality here, but also difference. In many indigenous Australian communities, land rights and resource and/or administrative development has brought internal differentiation and hints of stratification between individuals, family groups, and, sometimes, generations (see Taylor 2010: 48-49). Nonetheless, a number of Australianists would agree that there is relatively little one-way out-migration from Northern Territory homeland camps to regional towns or coastal cities. (This view is plausible rather than definitive; see Dombrowksi et al.'s paper). These writers point to a different formation aligned with indigenous people's relative estrangement from paid employment and commodity consumption. The stance is intended, in addition, to counter the lament among economists that Northern Territory indigenous people lack mobility and, thereby, market capacity for employment, the implication being that they must change. The counter view is that homelands-based indigenous people have great mobility, but of a different cultural kind (see, e.g., Peterson 2004; Prout 2014; Taylor 2011). Motor vehicles, especially in desert regions, facilitate very high levels of circular mobility between the homelands of a group's kinship network and regional service towns, a formation I describe as "spoke and hub" (see Austin-Broos 2014). But this mobility also involves funerals, family visits, ceremonial occasions, sporting carnivals, and land rights regional meetings. These locales are sometimes hundreds of miles from regional towns. A qualitative rendering of this milieu invokes the term "endosociality" in order to describe how "when travelling, [indigenous people] manage to avoid contact with the larger society, sitting with their backs to the world 'as if in conduits of their own making'" (Peterson 2004:235, citing Friedman 1997:284). Where Australianists commonly interpret this phenomenon simply as culture reproduced, elsewhere Friedman (2007), also with Ekholm-Friedman (1995), indicates that this "closing off" is a historically constituted sociality that needs analysis in each case. It is perhaps a further ethnographic route into the issue of networks, boundary making/marking, and the homophily of marginalized Inuit. Ensconced in bounded networks of the unemployed, job prospects invariably decrease (cf. Gray and Hunter 2005:387).

Ostensibly, the aboriginal and Inuit circumstances seem different, the former much less internally stratified and engaged with capitalist society. Yet both sites share acute social problems (see Dombrowksi et al.'s paper) indicative of their structural position in a global world. Possibly this reflects that the "culturally necessary victims" of Northern Territory indigenous Australiaelderly women and some men and the young incarcerated-for the present do not "move out" like Inuit but remain on homelands (Rebel 1989:119-120). Ethnographies should silence neither and look for the connections between them. 
Nobuhiro Kishigami

National Museum of Ethnology, 10-1 Senri Expo Park, Suita, Osaka 565-8511, Japan (inuit@idc.minpaku.ac.jp). 24 III 16

This paper is one of the few dealing with the current social situation and change among the Labrador Inuit following the successful completion of their land claim in 2005. Using new social network techniques, the authors explore social structure and boundaries of a nonaboriginal community in Labrador to which many coastal Labrador Inuit have migrated. As such, this paper is an ambitious and important contribution to Arctic anthropology. Thus, I have no hesitation in both congratulating the authors on a fine paper and rating highly their innovative research. Here, I attempt to make a few comments on the impacts of Inuit land claims on their home communities and out-migration from them.

As is well known, before the late 20th century many Canadian First Nations peoples left their home communities and resettled in nonaboriginal urban centers. Their voluntary out-migration was not directly related to any treaty or land claim. Among the Inuit of Canada, migration to several cities from their home communities in Nunavik and Nunavut became conspicuous from the 1980s or later. On the basis of my own research experiences in the Nunavik (Arctic Quebec) region and in Montreal over the past 30 years, it remains difficult to determine how the Nunavik land claim is related to their out-migration. However, I consider their recent pattern of migration to have been brought about by an enlarged penetration of the capitalist economy and that its resultant economic and political situations underlie their land claim. As a consequence, I hesitate to conclude that a direct causal relationship exists between Inuit land claims and their outmigration.

Since a few large Inuit communities (the regional political and economic centers such as Kuujjuaq and Inukjuak) have derived greater economic benefits than small communities (such as Akulivik and others in Nunavik), economic differences have been increasing among the communities after the James Bay and Northern Quebec Agreement (1975). In addition, economic stratification is emerging within each community. However, prominent economic, social, and demographic differences have not occurred among Nunavik Inuit communities that concluded the land claims agreement, such as Inukjuak and Kuujjuaraapik, and those that did not, such as Puvurnituq and Salluit. This shows that the social and economic impacts of the land claims on each Nunavik Inuit community seem to be much smaller than those of the prevailing capitalist economy, as well as the welfare and medical policies of the Quebec provincial government. Also, a social analysis of kinship, which is important in the daily life of the Inuit, is not paid enough attention in the paper.

As the authors point out regarding the coastal communities of the Labrador Inuit, most Nunavik Inuit communities show both a drastic natural population increase and increasing outmigration to southern cities. For comparative purposes, I wish to point out several characteristics of Nunavik Inuit migration (Kishigami 1999, 2006, 2008, 2013, 2015).

First, although local Nunavik Inuit recognize a rapid population increase in their home communities, they do not consider that a large number of Inuit migrate from their home communities either to one of several large Inuit communities whose population size is greater than 1,000 or to nonaboriginal cities. Rather, according to the 2011 Census of Canada, more than $25 \%$ of Inuit live in southern nonaboriginal urban areas (Kishigami 2015).

Second, more women than men leave their small communities for both the large Inuit settlements and/or nonaboriginal cities. Most Inuit migrants relocate as individuals unaccompanied by other family members from their native communities. Also, they tend to move to nonaboriginal cities, such as Edmonton, Montreal, and Ottawa, after living for a while in large Inuit communities (Kishigami 2013, 2015).

Third, there are clear differences in the reasons for migration between Inuit and First Nations (Indians) people in Canada. Whereas the causes of Inuit migration arise primarily from social problems in home communities, which include sexual and domestic violence, substance abuse, and shortage of housing, those of the First Nations people result mainly from seeking better jobs and higher education (Kishigami 2013).

Fourth, kinship functions to safeguard social safety in each Inuit home community. But once an Inuk leaves his or her community for places where he or she has few family members or kinsmen, he or she may lose the network. Thus, the number of homeless Inuit is increasing in both large Inuit communities in Nunavik and nonaboriginal cities in southern Canada.

These features of the Nunavik Inuit may also apply to the Labrador Inuit. I expect the authors to elaborate further on their ethnographic research methods and social network analysis techniques so as to make a comparative study of the impacts of Inuit land claims, migration, and social structure and change across the Arctic regions of Canada.

\section{Tess Lea}

Department of Gender and Cultural Studies, School of Philosophical and Historical Inquiry, University of Sydney, A14-Quadrangle, New South Wales 2006, Australia (tess.lea@sydney.edu.au). 30 III 16

I had to look up "redux" to understand the title. It is a literary term, referring to a bringing back or restorative movement, as when a movie is directed afresh with new or previously cut material. In this case, Dombrowski, Habecker, Gauthier, Khan, and Moses are revisiting and updating the way Inuit (and, more globally, other indigenous) relocations are approached methodologically, historically, and conceptually.

Conventionally, studies of indigenous social change track the struggles for land repossession and shifting relations of 
antagonism and alliance with the extractive industries and other development forces as part of an ethnographic capture of state manipulations, corporate interests, local political agency, and the fictions and frictions all these create when put together. While there is some recognition that land claims processes have created a new generation of winners and losers, there is less anthropological attention paid to the "silent migrations" that arise out of land claims and what the economic, biopolitical, and social ramifications might be.

These authors are troubled by — or rather want to renovatethis absence, drawing our attention to the Inuit who live in a community called Happy Valley-Goose Bay (HVGB) and the differences between people who have relocated at different historical junctures. Their method is intensely empirical, which is the article's chief provocation. They talk to lots of people-so far, so normal. The key difference is that they use the interview recruitment method itself as a data source. First-round interviewees were compensated with cash and three recruitment coupons to attract others to the interview process. The coupons operate like a radioactive iodine uptake scan: tracking who contacted who by following the coupons, the team identified different kinds of peer networks and group affiliations. Here we encounter a new form of anthropological redux: these forms of affiliation are given serious social networking names, like old-school anthropology with its talk of things like acephalous societies. Groups who bind themselves to each other exhibit homophily, unlike members of heterophilous groups, who interact with (unlike) others. When this networking information is interrogated beyond its role in correcting recruitment biases, hidden structural features are surfaced. A particular concern is with structures of internal inequality. Homophilous groups are more in-bound, lacking the kinds of relational resources that might help people overcome social isolation and economic marginality. Aboriginal people in the Northern Territory of Australia would call this having strong family and mean by this the ability to call on an extended range of resources and connections to make things happen. Here, Dombrowski and colleagues suggest that attention to such issues, to patterns of interconnection and nonconnection, can help explain the relationship between social affiliations, boundaries, and such consequential effects as housing status or the ability to hunt traditional foods because you have access to fuel, vehicles, rifles, kin, or buddies who will share the joy and pain of it.

Only the article does not quite say this. It imputes it. Because so much space is allocated to explaining the wider project from which this account of HVGB is drawn, why HVGB and then why subgroups within HVGB are the focus (versus the "whole community"), how the project was refined methodologically, and how such methods are both used normatively and used against their grain to ask new questions, and . . . ethnographic vignettes have been sacrificed. I suspect this comes from two related issues: the hoary issue of space and the need to explain the kinds of techniques that have now become unusual in cultural anthropology. This is methodological redux. In the process, details of lives as they are lived, of what the data mean in terms of richly populated interactions, are missing. It is an ironic side effect of trying to "restore" dispossession and relocation accounts from their more archetypal depictions: individuals are subordinated to technical data analyses.

It is my fervent hope that this article belongs to a planned series, where the narratives that could bring this painstakingly built data set to picaresque life are allowed more air. And if there is more to come, there is much we could yet learn. For instance, do the outsiders who "service" these communities or make policies that affect them know of the internal divisions that are being sketched here, or are they happy to meet with "tribal representatives" in ignorance of the kinds of internal stratification that also subtend the social harms policy may be attempting, however superficially, to ameliorate?

There are many teasers that beg elaboration and suggest the authors were hemming themselves in. For instance, why were the hypotheses chosen? What made the authors suspect that where one was born and when one migrated would have a greater impact on economic status and types of affiliation than other measures? And why exactly did people born along the coast migrate since the land claims era? These are the groups most likely to experience the most radical impoverishment and social isolation, but which is tail and which dog? There are hints that migration happens because of the social and individual chaos arising due to the confluence of land claims and ongoing industrial resource development. While better-off people were searching for employment and educational opportunities, others were escaping that chaos. These are hints that need drawing out, if only to contest the ongoing promotion of land title and resource negotiations as either the demonic source of all indigenous anomie or their magical remedy. The careful work that this article and the fuller project are founded on promise an ability to complicate our sense of the forces that are dragging people into even "harder lives in harder places" (Sider 2014:182). Such complication is vital, for anthropologists of settler colonialism need to be given tools for their most difficult of tasks: explaining the ecology of threats to indigenous lifeworlds beyond the false concretizations offered by the bad policy sociology that too often gets disguised as anthropology.

\section{Gro Ween}

Section for Ethnography, Museum of Cultural History, University of Oslo, Postboks 6762 St. Olavs plass, 0130 Oslo, Norway

(g.b.ween@khm.uio.no). 28 III 16

How to Reengage Relocation? Approaches to Inuit and Other Indigenous Population Movements and Inequalities in the Land Claims Era

Finding myself at a very different end of an anthropological spectrum from Dombrowski and colleagues, "Relocation Re- 
dux" is a fascinating read. I appreciate the large-scale fact production and the connections taken into consideration in the extensive mapping of variables. My own anthropological practice focuses on similar issues but from a qualitative ethnographic perspective, although not always of the traditional kind and not always with a village focus - and, possibly, with kindred ambition to tell other kinds of stories, with a broader perspective on who the involved are.

Dombrowski and colleagues make use of a quantitative social network methodology to attend to relocation. In the Arctic, "relocation" is a term many associate with particular historical forced movements. "Relocation Redux" broadens the term to provide a view of the structural violence involved in what the authors describe as a silent ongoing relocation from remote communities to regional hubs. This is one thread.

This new kind of relocation is associated with land claims processes, subsequent resource extraction, and what is called "transformation of culture politics." This is another thread. Migration, it is hypothesized, occurs because land claims may not bring desired social change. New resource extraction ventures may, contrary to expectations, not result in an economic little trickle-down effect. Often, people are left in worse conditions. With resource extraction, new workers are flown in from the outside, causing rises in social costs and new challenges to the social environment. All of these factors contribute to a lack of household resources and less control over resources and adds to substance abuse, lack of food security, family violence, and poor general health. For these reasons, although land claims valorize local lifestyles and traditions, the same process often brings developments that serve to undermine the same lifestyles. But in a given community these changes are not felt the same by all. New economic opportunities could come to those of privilege. This does not mean that only those of lesser privilege move. Migration, it appears, actually comes easier to the resourceful. This group tends to move for education or job opportunities, while socially marginal groups, according to the authors, move because of poverty or social problems.

Another thread here is that of indigeneity. The authors' suggest that land claims regimes narrow down definitions of indigeneity and produce constraints on possible identity projects and available opportunities. Consequent exclusion may contribute to other forms of social marginality and represent another reason for leaving. Ethnic differences, however, also reappear in another thread. The authors suggest that if we see the patterns of movement and social workings over time, it is not actually ethnic differences that produce social inequality. Rather, intergroup boundaries are better explained by past and present patterns of relocation interacting with currentday economic trends, producing two "distinct but overlapping systems of inequality."

The relations between the open meshwork of connections hypothesized in "Relocation Redux" and the actual methodology is not always obvious to me. As far as I can understand, the advantage of a social network approach is the openness that the analysis offers in terms of possible causal connections previously not considered.

As the reader understands, my impression is that "Relocation Redux" tells many loosely connected stories of migration in the Arctic. At the same time, the article presents quantified answers as percentages and gradients, providing a sense of precision. According to the authors, the large-scale quantitative material offers the opportunity to "observe" ethnic boundaries in action over time, taking into consideration land claims and ethnicity politics next to the workings of communities of different sorts, with their systems of stratifications. It is a sophisticated picture that is painted in the article, although not always entirely clear. Some of the precision is, in my opinion, lost in the narrow framing of the actual network investigations. The analytical tools put to use here are homophily versus heterophily, categories that measure people's tendency to interact with people inside or outside the group over time. The groups in question are classified as relating to ethnic identity, place of birth, and income.

This narrowing of focus from the open, heterogeneous set of possible relations outlined in the introductory parts is in a way dramatic. Several assumptions affecting the connections hypothesized are left behind. Examples of these are the connections between the changes in identity productions corresponding with land claims, the expectations of locals following successful land claims, and how kinship and friendship is negotiated across socioeconomic class and ethnic identities.

In indigenous worlds there are, as "Relocation Redux" also confirms, many reasons for moving between remote areas and regional centers and many kinds of movement, some forced, some voluntary, and some more permanent than others. In contemporary indigenous politics, ethnic identification might be nurtured both from deeply negative experiences, such as forced relocation, and from positive experiences of successful land claims. Many anthropologists, including Australians Lea and Cowlishaw (2010), who are quoted in the article, provide perspectives on the complexities of urban and remote conditions involving identity; subsistence practices; benefits agreements; material conditions; conditions of work and education; interaction with health, education, and bureaucratic systems; and negotiations of messy indigeneities.

Taking the structure of the article into consideration, with its shifts between loose framework and precise quantifications of smaller material, in my opinion suggest that to the authors, social network analysis provides an opportunity to ask new questions and to transgress the known by offering large materials of social trends over time. But to reformulate the authors' final words, for "views that place both indigenous communities' choice of struggles and our own choice of ethnographic objects in the context of contemporary global processes" we must also look elsewhere. 


\section{Reply}

We thank the discussants for their generous and thoughtful comments. These comments are generally of two kinds. Arzyutov, Austin-Broos, and Kishigami offer valuable comparison cases from a range of locations near and far to the case considered here, from nearby Nunavik to distant Australia and Siberia. Together they note some important commonalities and some of what they see as significant differences. A second set of comments from Lea and Ween engage the research strategy with a mixture of interested questions inspired by the somewhat novel methods employed here and other more searching questions about what may be missed by this (re)turn to what might seem to some like a past social structuralism. We respond to these two sets of comments separately.

Austin-Broos, drawing on a critical early article by Peterson (1986), points to a missing element in many ethnographic accounts of indigenous land claims - that land claims entail both more and less than a simple and overdue renegotiation of a relationship between settler states and aboriginal claimants. This missing element is global capitalism, mainly in the form of industrial resource extraction, which did not feature as significantly in our essay as it has in other work from the same study. Elsewhere we have attempted to link current economic marginality in sending communities to both historical events of settlement and current industrial development (Dombrowski et al. 2013c, 2014). While not the focus here, we certainly agree that the missing link between the land claims process and its eventual impact on many small aboriginal communities is the economic development aspirations that often lie (in unequal proportion) behind both sides of land claims negotiations.

As Austin-Broos notes, scarcely behind the curtain of indigenous land claims negotiations, these actors and structures render "historical rights" and "sovereignty claims" in a related but quite distinct language of market processes and titled properties. Elsewhere, Dombrowski has argued that, in the United States, larger national class dynamics informed these processes (Dombrowski 2007, 2008), with implications for environmental movements and many other groups. In Australia, Austin-Broos notes by way of contrast that this process has been more connected to welfare state concerns of encapsulated governance and less to class dynamics located outside the indigenous communities themselves (Austin-Broos 2011; Lea 2008). The result there is an "endosociality" that provides few links to a surrounding political economy, or at least few links that are not brokered by government actors and NGO surrogates.

In contrast to both of these situations, in Canada, with many First Nation and Inuit people remaining in remote locations (as is the case in Australia), the central trope for remote communities has been labor (Bell 2014). Aboriginal claimants have been told repeatedly that what they lack is jobs, and the question is just how much of their claims they ought to surrender in order to get them. Whether and how those jobs eventually appeared seems to have been an afterthought in many cases, the importance of which only becomes clear long after a land settlement is in place (Dombrowski et al. 2013a). The emerging and novel socialities of remote communities that results from job-centric settlements remains largely absent from the picture drawn here because our focus was on the social situation of those who had left rather than the social situations that caused them or allowed them to do so. As noted only briefly in the current essay, however, many postsettlement communities have seen a net in-migration, often as indigenous and nonindigenous people move to land claims areas for the jobs that are created by the claims settlement agreement. This has resulted in housing shortages and increases in local prices for just about everything, as demand and cash flow increase in previously enclosed locations.

For those in the community who are unable or do not want to be part of this process, their ability to remain is eroded even if their circumstances change very little as a result of the claims process. For them, there is the sensation (to paraphrase Sidney Mintz) of moving while standing still (Mintz 1989). The result, in Labrador anyway, is quite different from the regional endosociality that Austin-Broos discusses. Here-and elsewhere in Canada, we suspect - a sort of endosociality is more often found in the receiving communities to which people eventually move. In seeking to measure this and draw comparisons, we use an analytical rendering of the notion of homophily-but other, more qualitative descriptions of life in receiving communities are also available (Samson 2003; Sider 2014).

Clearly this process is far from uniform across history or geography, but the exceptions may help prove the rule. Arzyutov describes the situation in the Russian Arctic where forced relocation and settlement were met with an almost immediate return to more remote locations, only to find later that some of those fleeing sedentarization move voluntarily to even larger cities beyond their state-intended villages. We do not get a sense of the role played by capitalist firms (or even Soviet-style state-capital projects) in this process, and perhaps there was none. The latter might explain both why people found it easy to leave settlement villages (and were allowed to do so), and why they returned later to the cities. It also provides a different sort of perspective on why so few land claims in the region have been heard by the current Russian government. If there is no pressing need to deny people access to land (either to use it for some other purpose or to compel them into work), then the actual dispossession that fuels land claims movements remains absent. This situation was common in Labrador before the discovery of significant mineral resources at Voisey's Bay (Brice-Bennett 1977).

In contrast, Kishigami notes the earlier and direct capital penetration into neighboring Nunavik and its role in prompting out-migration from villages to regional centers like Kuujjuaq - much of which is rooted in increasing village-level inequalities that followed the James Bay Agreement. He sees 
this, and not a land claims process itself, as driving the movement of Inuit within and out of Nunavik. This might be splitting hairs, as the development that happened around James Bay was put in place by a large land settlement agreement, elements of which were very familiar to land claims settlements in Alaska at the time (early 1970s) — involving large one-time cash settlements and the creation of for-profit Alaska Native Corporations (Dombrowski 2014). To our mind, the issue of direct and indirect "causation" is less important than the fact that such process seemed joined at the hip, and the end results are both predictable and too often ignored by other anthropologists. Kishigami's past work is a notable exception here (Kishigami 2008), and his research undertaken to document the out-migration of Nunavik stands as a critical ethnographic correction to village-centric approaches that have otherwise dominated Arctic anthropology.

As Kishigami points out, the bulk of Canadian Arctic Inuit out-migration seems to be directed, eventually, to large, nonaboriginal cities like Montreal or Ottawa (or Yellow Knife or Edmonton; Young and Moses 2013), often after living in one of the regional centers. Anecdotal evidence from our own work would tend to agree with these findings, though we did not collect data outside Labrador to corroborate this. If it is the case that Inuit outside Labrador are leaving small northern communities for regional centers and then onward to the margins of larger North American cities, it would seem to us to offer further generality to our findings from HVGB: that few of the Inuit or First Nations people who move to regional centers find opportunities for social integration there.

In all, these comments help extend the potential implications of the research presented here, and we appreciate both the contrasts and the comparisons. Throughout much of the indigenous world it seems clear that in our current age of unapologetic market triumphalism, such processes are not actually shrouded in much secrecy at all. In Canada, the process whereby land claims properties will be commodified and put into the hands of industrial resource developers has become a precondition of formal government/First Nation or Inuit negotiations. Labeled "impact benefit agreements," these ostensibly confidential agreements put capital's interests at the front of the claims process (Hitch and Fidler 2007). Similar processes can be found in Australia and the United States as well (Dombrowski 2010). Yet despite more than two decades of impact in indigenous communities across the Arctic, they are all but absent for any ethnographic mention. The lesson is stark: as Austin-Broos notes in her comment, "capital and state articulate, not merely frame, local socialities and histories" (see also Sider 2014).

Ween and Lea raise a separate set of issues for consideration, the extent to which the "methodological redux" at the heart of the analysis leaves "individuals ... subordinated to technical data analyses," as Lea notes. As both comments imply, the current article cuts against the grain of recent anthropological methods. Lea's choice of terms is perhaps unintentionally revealing, however, of what we see as the more significant meth- odological shift inherent in the approach here. That is, while the network analysis techniques used here may remind anthropologists of early ethnography's concerns with formalisms, the real break, as we see it, is with contemporary cultural anthropology's implicit methodological individualism - the idea that what we see happening on the supraindividual scale of countries, classes, or even everyday collectivities can be explained solely by reference to what Talcott Parson's called the individual's action frame of reference (Parsons, Shils, and Smelser 1965). The latter amounts to the sorts of answers we get when we ask, "Why did you do that?" The difference in methodology here, as we see it, is not an outsized insistence on the empiricaljust about all contemporary cultural anthropologists talk to people and base what they write on what is said in those conversations. The change is the focus on an ethnographic object that is larger than the individuals themselves - larger in the sense that it looks at groups and not individuals, and larger in the sense that it approaches such phenomena as more than the results of their individual thoughts, imaginings, and ontologies of various sorts.

As Asad (2009) once pointed out, judging the visible as somehow "more real" than the invisible is an old empiricist prejudice - the opinion that the actions of a person voting are somehow more real than a voting trend because the latter can be captured only abstractly in words or in a graph. Such a prejudice pushes methodological individualism to the fore. With this in mind, it bears asking whether it makes much difference whether those involved in moving out from the coast could put a name to their reasons for doing so or whether such a thing as having "a reason" or "a motive" for moving away is even a realistic expectation by the researcher. This is not to say that the latter, where they do exist, are unimportant. It is simply to say that these things, the chorus of proximal reasons, stated motives, and explanations drawn from personal subjective schemes, may not be sufficient explanation for what is actually going on, even when considered in their entirety (which they seldom are). In fairness, both Lea and Ween are careful to see a focus on subjective experience as complementary to the one advanced here, and we agree. The question we wish to raise is whether and how much cultural anthropology as a discipline has gone down this particular Parsonian path without realizing it.

Relatedly, Ween also takes issue with what might at one point have been criticized as the "reductionism" inherent our approach: the shift between the "loose framework and precise quantifications" of the material. This is correct to the point of tautology - to be amendable to the sort of analysis performed in our article, representation (and indeed simple, perhaps simplistic representation) was necessary. Much is lost in such a process. This is part of the problem with that "invisible" world of relationships that Asad alludes to. Relationships cannot be seen or understood without being represented.

Under such circumstances, the need for many representations of the same relationship is clear if we are to have a fuller picture. The methods used here can be duplicated else- 
where for purposes of comparison in a way that less precise methods cannot, and they can be tracked through time to reveal changes unrealized by those involved. In this way they may be useful in ways that are tied specifically to their simplicity and their precision. Ween realizes this, of course. Maps too are simplifications, useful for their ability to render spatial relationships visible despite the fact that most aspects of the actual land or territory are eliminated in the process (Ween 2012). Our caution to a cultural anthropology that has largely lost interest (and ability) in the sorts of formal representations used here is that by doing so, anthropology puts in place an implicit and largely unmarked ranking on the myriad representational forms at its disposal. There may be good reasons for such a ranking, but disciplinary habit is unlikely to be one of those reasons.

—Kirk Dombrowski, Patrick Habecker, G. Robin Gauthier, Bilal Khan, and Joshua Moses

\section{References Cited}

Abdul-Quader, A. S., D. D. Heckathorn, K. Sabin, and T. Saidel. 2006. Implementation and analysis of respondent driven sampling: lessons learned from the field. Journal of Urban Health 83(suppl. 1):1-5. http://doi.org /10.1007/s11524i006-9108-8.

Abele, F., N. Falvo, and A. Hache. 2010. Homeless in the homeland: a growing problem for indigenous people in Canada's North. Parity 23(9):21.

Amagoalik, J. 2008. Reconciliation or conciliation? an Inuit perspective. In From truth to reconciliation: transforming the legacy of residential schools. Prepared for the Aboriginal Healing Foundation by Marlene Brant Castellano, Linda Archibald, and Mike DeGagné. Pp. 92-97. Ottawa: Aboriginal Healing Foundation.

Argounova-Low, Tatiana. 2007. Close relatives and outsiders: village people in the city of Yakutsk, Siberia. Arctic Anthropology 44(1):51-61. [DVA]

Asad, Talal. 2009. Genealogies of religion: discipline and reasons of power in Christianity and Islam. Baltimore, MD: JHU Press.

Austin-Broos, D. 2006. "Working for" and "working" among Western Arrernte in Central Australia. Oceania 76(1):1-15. [DA-B]

- 2009. Arrernte present, Arrernte past: invasion, violence, and imagination in indigenous Central Australia. Chicago: University of Chicago Press.

. 2011. A different inequality: the politics of debate about remote Aboriginal Australia. Crow's Nest: Allen \& Unwin.

. 2014. The debate concerning remote indigenous communities. Keynote Address, Supreme and High Court Judges of Australia, Annual Conference, Darwin, July 7-9. [DA-B]

Ballard, C., and G. Banks. 2003. Resource wars: the anthropology of mining Annual Review of Anthropology 32:287-313.

Balser, Marjorie M. 2016. Indigeneity, land and activism in Siberia. In Land, indigenous peoples and conflict. Alan C. Tidwell and Barry S. Zellen, eds Pp. 9-27. London: Routledge. [DVA]

Befu, H. 1977. Social exchange. Annual Review of Anthropology 6(1):255-281. http://doi.org/10.1146/annurev.an.06.100177.001351.

Bell, Lindsay. 2014. Diamonds as development: suffering for opportunity in the Canadian North. Accessed July 7, 2016. https://tspace.library.utoronto.ca /handle/1807/65502.

Ben-Dor, S. 1977. Inuit-settler relations in Makkovik, 1962. In The white Arctic: anthropological essays on tutelage and ethnicity. Robert Paine, ed. Pp. 306-325. Memorial University of Newfoundland. Toronto: University of Toronto.

Berchenko, Y., J. Rosenblatt, and S. D. W. Frost. 2013. Modeling and analysing respondent driven sampling as a counting process. arXiv e-print 1304.3505. http://arxiv.org/abs/1304.3505.

Branch, L. S. 2005. Consolidated federal laws of Canada, Labrador Inuit Land Claims Agreement Act. Accessed March 4, 2014. http://laws-lois.justice.gc.ca /eng/acts/L-4.3/.

Brice-Bennett, C. 1977. Our footprints are everywhere: Inuit land use and occupancy in Labrador. Nain: Labrador Inuit Association.
— 1994. Dispossessed: the eviction of Inuit from Hebron Labrador (a report to North Program, Royal Commission on Aboriginal Peoples). Happy Valley-Goose Bay: Labrador Institute, Memorial University of Newfoundland. Burns, A. 2006. Moving and moving forward: Mushuau Innu relocation from Davis Inlet to Natuashish. Acadiensis 35(2):64-84.

Chance, N. A. 1960. Culture change and integration: an Eskimo example. American Anthropologist 62(6):1028-1044.

- 1990. The Inupiat and Arctic Alaska. Fort Worth, TX: Holt, Rinehart, \& Winston.

Chandler, M., and C. Lalonde. 1998. Cultural continuity as a hedge against suicide in Canada's First Nations. Transcultural Psychiatry 35(2):191-219. http://doi.org/10.1177/136346159803500202.

Chandler, M., C. E. Lalonde, B. W. Sokol, D. Hallett, and J. E. Marcia. 2003. Personal persistence, identity development, and suicide: a study of Native and non-Native North American adolescents. Monographs of the Society for Research in Child Development 68(2):i-138.

Chandler, M., and T. Proulx. 2006. Changing selves in changing worlds: youth suicide on the fault-lines of colliding cultures. Archives of Suicide Research 10(2):125-140. http://doi.org/10.1080/13811110600556707.

Christensen, J. 2012. "They want a different life": rural northern settlement dynamics and pathways to homelessness in Yellowknife and Inuvik, Northwest Territories. Canadian Geographer/Le Géographe Canadien 56(4):419438

Clifford, J. 2013. Returns: becoming indigenous in the twenty-first century. Cambridge, MA: Harvard University Press.

Collier, P. 2008. The bottom billion: why the poorest countries are failing and what can be done about it. Oxford: Oxford University Press.

Cook, K. S., C. Cheshire, E. R. Rice, and S. Nakagawa. 2013. Social exchange theory. Dordrecht: Springer.

Cowlishaw, G. 2009. The city's outback. Sydney: UNSW Press.

Cowlishaw, G., and T. Lea. 2010. Development, heroism and the indigenous life project. Dialectical Anthropology 34(2):223-234.

Cunsolo Willox, A., S. L. Harper, J. D. Ford, K. Landman, K. Houle, and V. L. Edge. 2012. "From this place and of this place": climate change, sense of place, and health in Nunatsiavut, Canada. Social Science and Medicine 75 (3):538-547.

Damas, D. 2004. Arctic migrants/Arctic villagers: the transformation of Inuit settlement in the central Arctic. Montreal: McGill-Queen's University Press.

Dombrowski, Kirk. 2002. The praxis of indigenism and Alaska Native timber politics. American Anthropologist 104(4):1062-1073.

. 2007. Subsistence livelihood, Native identity and internal differentiation in southeast Alaska. Anthropologica 49(2):211-229.

. 2008. Reply: what's changed (since 1975)? Dialectical Anthropology 32(1/2):43-50. http://doi.org/10.1007/s10624-008-9055-8.

- 2010. The white hand of capitalism and the end of indigenism as we know it. Australian Journal of Anthropology 21(1):129-140.

. 2014. Culture politics: the story of native land claims in Alaska. Lincoln, NE: Syron Design Academic.

Dombrowski, Kirk, Emily Channell, Bilal Khan, Joshua Moses, and Evan Misshula. 2013a. Out on the land: income, subsistence activities, and food sharing networks in Nain, Labrador. Lournal of Anthropology 2013(1):1-11. http://doi.org/10.1155/2013/185048.

Dombrowski, Kirk, Bilal Khan, Emily Channell, Joshua Moses, Kate McLean, and Evan Misshula. 2013b. Kinship, family, and exchange in a Labrador Inuit community. Arctic Anthropology 50(1):89-104.

Dombrowski, Kirk, Bilal Khan, Joshua Moses, Emily Channell, and Nathanie Dombrowski. 2014. Network sampling of social divisions in a rural Inuit community. Identities 21(2):134-151.

Dombrowski, Kirk, Bilal Khan, Joshua Moses, Emily Channell, and Evan Misshula. 2013c. Assessing respondent driven sampling for network studies in ethnographic contexts. Advances in Anthropology 3(1):1-9.

Duffy, R. Q. 1988. The road to Nunavut: the progress of the eastern Arctic Inuit since the Second World War. Montreal: McGill-Queen's Press.

Ekholm-Friedman, K., and J. Friedman. 1995. Global complexity and the singularity of everyday life. In Worlds apart: modernity through the prism of the local. D. Miller, ed. Pp. 134-168. London: Routledge. [DA-B]

Fondahl, Gail, Olga Lazebnik, Greg Poelzer, and Vasily Robbek. 2001. Native "land claims," Russian style. Canadian Geographer/Le Géographe Canadien 45(4):545-561. doi:10.1111/j.1541-0064.2001.tb01501.x. [DVA]

Fondahl, Gail, and Greg Poelzer. 2003. Aboriginal land rights in Russia at the beginning of the twenty-first century. Polar Record 39(02):111-122. doi:10 $.1017 /$ S0032247402002747. [DVA] 
Friedman, J. 1997. Simplifying complexity. In Siting culture: the shifting anthropology subject. K. F. Olwig and K. Hastrup, eds. Pp. 268-291. London Routledge. [DA-B]

- 2007. Global systems, globalization, and anthropological theory. In Frontiers of globalization research: theoretical and methodological approaches. I. Rossi, ed. Pp. 109-132. Berlin: Springer. [DA-B]

Gile, K. J., and M. S. Handcock. 2010. Respondent-driven sampling: an as sessment of current methodology. Sociological Methodology 40(1):285-327. http://doi.org/10.1111/j.1467-9531.2010.01223.x.

Glasser, I. 1997. On being Native and homeless on the streets of Montréal. City and Society 9(1):263-265.

Goel, S., and M. J. Salganik. 2009. Respondent-driven sampling as Markov chain Monte Carlo. Statistics in Medicine 28(17):2202-2229. http://doi.org $/ 10.1002 / \operatorname{sim} .3613$.

2010. Assessing respondent-driven sampling. Proceedings of the National Academy of Sciences of the United States of America 107(15):67436747.

Golovnev, Andrei V. 1995. Govoriaschie kultury: traditsii samodiitsev i ugrov. Sergei A. Arutiunov, ed. Ekaterinburg: UrO RAN. [DVA]

Gray, M., and B. Hunter. 2005. The labour market dynamics of indigenous Australians. Journal of Sociology 41(4):386-405. [DA-B]

Heckathorn, D. D. 2002. Respondent-driven sampling II: deriving valid population estimates from chain-referral samples of hidden populations. Social Problems 49(1):11-34.

2007. Extensions of respondent-driven sampling: analyzing continuous variables and controlling for differential recruitment. Sociological Methodology 37(1):151-207.

Hicks, J., and G. White. 2000. Nunavut: Inuit self-determination through a land claim and public government. In Nunavut: Inuit regain control of their lands and their lives. Jens Dahl, Jack Hicks, and Peter Jull, eds. Pp. 30-115. Copenhagen: International Work Group for Indigenous Affairs.

Hitch, Michael, and Courtney Riley Fidler. 2007. Impact and benefit agreements: a contentious issue for environmental and aboriginal justice. Environments Journal 35(2):45-69.

Holzlehner, Tobias. 2011. Engineering socialism: a history of village relocations in Chukotka, Russia. In Engineering Earth: the impacts of megaengineering projects. Stanley D. Brunn, ed. Pp. 1957-1973. Dordrecht: Springer. [DVA]

Hunn, E. S., D. R. Johnson, P. N. Russell, and T. F. Thornton. 2003. Huna Tlingit traditional environmental knowledge, conservation, and the management of a "wilderness" park. Current Anthropology 44(suppl.):S79-S103.

Jackson, J. E., and K. B. Warren. 2005. Indigenous movements in Latin America, 1992-2004: controversies, ironies, new directions. Annual Review of Anthropology 34:549-573.

James, M. 2008. Wrestling with the past: apologies, quasi-apologies, and nonapologies in Canada. In The age of apology: facing up to the past. Mark Gibney, Rhoda E. Howard-Hassmann, Jean-Marc Coicaud, and Niklaus Steiner, eds. Pp. 144-145. Philadelphia: University of Pennsylvania Press.

Kennedy, J. C. 1977. Local government and ethnic boundaries in Makkovik, 1972. In The white Arctic: anthropological essays on tutelage and ethnicity. Robert Paine, ed. Pp. 359-375. St. John's: Memorial University of Newfoundland.

- 1982. Holding the line: ethnic boundaries in a northern Labrador community. St. John's: Institute of Social and Economic Research, Me morial University of Newfoundland.

Kermode-Scott, B. 2005. Canadian life expectancy varies greatly depending on ethnic origin. British Medical Journal 330(7487):326.

King, U., and C. Furgal. 2014. Is hunting still healthy? understanding the interrelationships between indigenous participation in land-based practices and human-environmental health. International Journal of Environmental Research and Public Health 11(6):5751-5782.

Kirmayer, L. J., L. J. Boothroyd, and S. Hodgins. 1998. Attempted suicide among Inuit youth: psychosocial correlates and implications for prevention. Canadian Journal of Psychiatry 43(8):816-822.

Kishigami, Nobuhiro. 1999. Why do Inuit move to Montreal? a research note on urban Inuit. Etudes/Inuit/Studies 23(1/2):221-227. [NK]

. 2006. Inuit social networks in an urban setting. In Critical Inuit studies: an anthology of contemporary Arctic ethnography. P. Stern and L. Stevenson, eds. Pp. 206-216. Lincoln: University of Nebraska Press. [NK] . 2008. Homeless Inuit in Montréal. Études/Inuit/Studies 32(1):73-90. 2013. The Inuit's migration patterns and drastic population increase in urban centers of Canada. In Cultural challenges of migration in Canada (Canadiana 12). Klaus-Dieter Ertler and Patrick Lambert, eds. Pp. 65-73. Frankfurt: Peter Lang. [NK]
2015. Low-income and homeless Inuit in Montreal, Canada: report of a 2012 research. Bulletin of the National Museum of Ethnology 39(4):575624. [NK]

Krupnik, Igor, and Mikhail Chlenov. 2007. The end of "Eskimo Land": Yupik relocation in Chukotka, 1958-1959. Études/Inuit/Studies 31(1/2):59-81. [DVA]

Kulchyski, P. K. 2005. Like the sound of a drum: aboriginal cultural politics in Denendeh and Nunavut. Cambridge: Cambridge University Press.

Kuper, A. 1988. The invention of primitive society: transformations of an illusion. London: Routledge.

Laptander, Roza. 2014. Processes of remembering and forgetting: Tundra Nenets' reminiscences of the 1943 Mandalada rebellions. Sibirica 13(3):2244. doi:10.3167/sib.2014.130302. [DVA]

Larsen, P. B. 2015. Post-frontier resource governance: indigenous rights, extraction and conservation in the Peruvian Amazon. New York: Palgrave Macmillan.

Lea, Tess. 2008. Bureaucrats and bleeding hearts: indigenous health in northern Australia. Sydney: UNSW Press.

. 2012. When looking for anarchy, look to the state: fantasies of regulation in forcing disorder within the Australian indigenous estate. Critique of Anthropology 32(2):109-124.

Lezova, Svetlana V. 2001. Severnyi Yamal: Velikoe Pereselenie 1947 Goda. In Samodiitsy: Materialy IV Sibirskogo Simposiuma "Kul'turnoe Nasledie Narodov Zapadnoi Sibiri” (1-12 Dekabrya 2001 G., Tobol'sk). Andrei V. Golovnev, ed. Pp. 132-135. Tobol'sk: Omsk. [DVA]

Li, T. M. 2014. Land's end: capitalist relations on an indigenous frontier. Durham, NC: Duke University Press.

Marcus, A. R. 1991. Out in the cold: Canada's experimental Inuit relocation to Grise Fiord and Resolute Bay. Polar Record 27(163):285-296.

- 1995. Relocating Eden: the image and politics of Inuit exile in the Canadian Arctic. Hanover, NH: Dartmouth College, University Press of New England.

Mintz, Sidney W. 1989. The sensation of moving, while standing still. American Ethnologist 16(4):786-796.

Mouw, T., and A. M. Verdery. 2012. Network sampling with memory: a proposal for more efficient sampling from social networks. Sociological Methodology 42(1):206-256.

Murray Li, T. 2000. Articulating indigenous identity in Indonesia: resource politics and the tribal slot. Comparative Studies in Society and History 42 (1):149-179.

Natcher, D. C., and A. H. Procter. 2012. Settlement, subsistence, and change among the Labrador Inuit: the Nunatsiavummiut experience, vol. 2. Winnipeg: University of Manitoba Press.

Nguyen, D., J.-F. Proulx, J. Westley, L. Thibert, S. Dery, and M. A. Behr. 2003. Tuberculosis in the Inuit community of Quebec, Canada. American Journal of Respiratory and Critical Care Medicine 168(11):1353-1357.

Novikova, Natalia I. 2014. Okhotniki I Neftianiki: Issledovanie Po Iuridicheskoi Antropologii. Moscow: Nauka. [DVA]

Oliver, L. N., P. A. Peters, and D. E. Kohen. 2012. Mortality rates among children and teenagers living in Inuit Nunangat, 1994 to 2008. Statistics Canada 23(3):1-6.

Paine, R. 1977. Tutelage and ethnicity, a variable relationship. In White Arctic: anthropological essays on tutelage and ethnicity. Robert Paine, ed. Pp. 249263. St. John's: Institute of Social and Economic Research, Memorial University of Newfoundland.

Pallot, Judith. 1999. Land reform in Russia, 1906-1917: peasant responses to Stolypin's project of rural transformation. Oxford: Clarendon. [DVA]

Parsons, Talcott, Edward Albert Shils, and Neil J. Smelser. 1965. Toward a general theory of action: theoretical foundations for the social sciences. Piscataway, NJ: Transaction.

Peters, P. A. 2010. Causes and contributions to differences in life expectancy for Inuit Nunangat and Canada, 1994-2003. International Journal of Circumpolar Health 69(1):38-49.

Peterson, N. 1986. Capitalism, culture and land rights: Aborigines and the state in the Northern Territory. Social Analysis 18:85-101. [DA-B] . 2004. Myth of the walkabout: movement in the aboriginal domain. In Population, mobility and indigenous peoples in Australasia and North America. J. Taylor and M. Bell, eds. Pp. 223-238. London: Routledge. [DA-B]

Procter, A. 2012. Nunatsiavut land claims and the politics of Inuit wildlife harvesting. Settlement, subsistence and change among the Labrador Inuit: the Nunatisvummiut experience. David C. Natcher, Lawrence Felt, and Andrea Procter, eds. Pp. 189-208. Winnipeg: University of Manitoba Press. 
Prout, S. 2014. Interrogating the image of the "wandering nomad." In $A b$ original populations: social, demographic and epidemiological perspectives. F. Trovato and A. Romaniuk, eds. Pp. 381-414. Edmonton: University of Alberta Press. [DA-B]

Rebel, H. 1989. Cultural hegemony and class experience: a critical reading of recent ethnological-historical approaches (part one). American Ethnologist 16(1):117-136.

Salganik, M. J., and D. Heckathorn. 2004. Sampling and estimation in hidden populations using respondent-driven sampling. Sociological Methodology 34(1):193-240. http://doi.org/10.1111/j.0081-1750.2004.00152.x.

Samson, Colin. 2003. A way of life that does not exist: Canada and the extinguishment of the Innu, vol. 67. New York: Verso.

Scott, C. 2011. Aboriginal autonomy and development in northern Quebec and Labrador. Vancouver: UBC Press.

Sider, Gerald. 2006. The production of race, locality, and state: an anthropology. Anthropologica 48(2):247-263. http://doi.org/10.2307/25605314.

. 2014. Skin for skin: death and life for Inuit and Innu. Durham, NC: Duke University Press.

Spiller, M. W., C. Cameron, and D. D. Heckathorn. 2012. RDSAT 7.1 User manual: RDS analysis tool 7.1. Ithaca, NY: Cornell University.

Stammler, Florian. 2005. Reindeer nomads meet the market: culture, property and globalisation at the "End of the Land," vol. 6. Halle Studies in the Anthropology of Eurasia. Munster: Lit. [DVA]

Statistics Canada, Government of Canada. 2013. 2011 National Household Survey Profile-Census Subdivision. Accessed March 4, 2014. http://www12 .statcan.gc.ca/nhs-enm/2011/dp-pd/prof/details/page.cfm?Lang =E\&Geol $=$ CSD $\&$ Code $1=1010025 \&$ Data $=$ Count $\&$ SearchText $=$ Happy $\% 20$ Valley - Goose $\% 20$ Bay\&SearchType $=$ Begins $\&$ SearchPR $=01 \& A 1=$ All $\& B 1=$ All $\& \mathrm{TABID}=1$.

Stewart, M. 2013. Roma and Gypsy "ethnicity" as a subject of anthropological inquiry. Annual Review of Anthropology 42:415-432.

Sutton, P. 2011. The politics of suffering: indigenous Australia and the end of the liberal consensus (new edition). Carlton: Melbourne University Publishing.

Taylor, C. 1994. The politics of recognition. In Multiculturalism: examining the politics of recognition. Amy Gutmann, ed. Pp. 25-75. Princeton, NJ: Princeton University Press.

Taylor, J. 1979. Indian-Inuit relations in eastern Labrador, 1600-1976. Arctic Anthropology 16(2):49-58
2010. Demography as destiny: schooling, work and Aboriginal population change in Wadeye. CAEPR Working Paper 64/2010. Canberra: Centre for Economic Policy Research. [DA-B]

. 2011. Beyond the pale: measures of mobility in postcolonial Australia. Law Text Culture (15):72-99. [DA-B]

Tester, F. J., and P. K. Kulchyski. 1994. Tammarniit (mistakes): Inuit relocation in the eastern Arctic, 1939-63. Vancouver: UBC Press.

Wakeham, P. 2012. Reconciling "terror": managing indigenous resistance in the age of apology. American Indian Quarterly 36(1):1-33.

Ween, Gro B. 2012. World heritage and indigenous rights: Norwegian examples. International Journal of Heritage Studies 18(3):257-270.

Wejnert, C. 2009. An empirical test of respondent-driven sampling: point estimates, variance, degree measures, and out-of-equilibrium data. Sociological Methodology 39(1):73-116. http://doi.org/10.1111/j.1467-9531.2009.01216.x.

- 2010. Social network analysis with respondent-driven sampling data: a study of racial integration on campus. Social Networks 32(2):112-124. http://doi.org/10.1016/j.socnet.2009.09.002.

Wejnert, C., D. D. Heckathorn, J. Ramirez-Valles, and R. M. Diaz. 2008. The dual homophily model: disentangling the effects of affiliation preference and differential degree on homophily. Paper presented at the annual meeting of the American Sociological Association Annual Meeting, Sheraton Boston and Boston Marriott Copley Place, Boston, MA.

Whitbeck, L. B., X. Chen, D. R. Hoyt, and G. W. Adams. 2004. Discrimination, historical loss and enculturation: culturally specific risk and resiliency factors for alcohol abuse among American Indians. Lournal of Studies on Alcohol 65 (4):409-418.

Widdowson, F., and A. Howard. 2008. Disrobing the aboriginal industry. Montreal: McGill-Queen's University Press.

Wilkins, R., S. Uppal, P. Finès, S. Senécal, É. Guimond, and R. Dion. 2008. Life expectancy in the Inuit-inhabited areas of Canada, 1989 to 2003. Health Reports/Statistics Canada, Canadian Centre for Health Information/Rapports Sur La Sante/Statistique Canada, Centre Canadien D'information Sur La Sante 19(1):7-19.

Wimmer, A. 2013. Ethnic boundary making: institutions, power, networks. Oxford: Oxford University Press.

Young, Michael G., and Joshua Moses. 2013. Neoliberalism and homelessness in the western Canadian Arctic. Canadian Journal of Nonprofit and Social Economy Research 4(2):7-22. Accessed July 15, 2016. http://anserj.ca/index .php/cjnser/article/view/147. 
Equilibrium in respondent driven sampling (RDS) indicates a point at which an RDS sample reaches stability in the proportion of people who are recruited in respect to various attributes of interest. The figures presented in this appendix show how the proportion of the sample changes over the course of the data collection period by several different attributes of interest. As displayed here, equilibrium is visually detected by a flattening of the line across time as the sample proportions stabilize. Attributes with a small number of categories (see $\mathrm{A} 1 \mathrm{for}$ a dichotomous example) are often easier to decipher, but equilibrium can be at times be detected visually even in more complex divisions (see A5 or A6). For RDS, equilibrium remains an important diagnostic criterion to examine whether the sampling process has moved across divisions in a sample population. This appendix displays equilibrium graphs for nine focal attributes in the Happy Valley Goose Bay (HVGB) community.

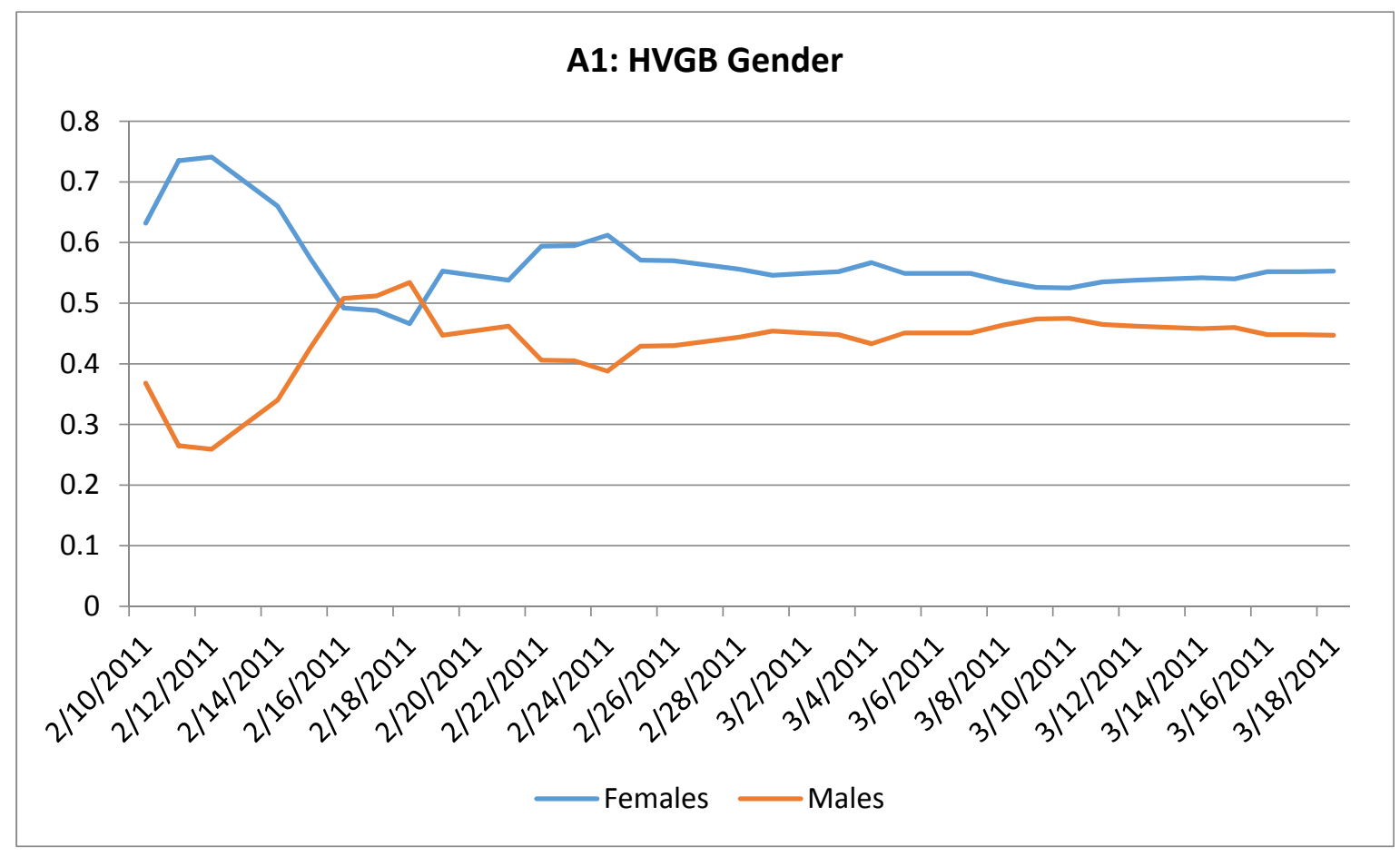



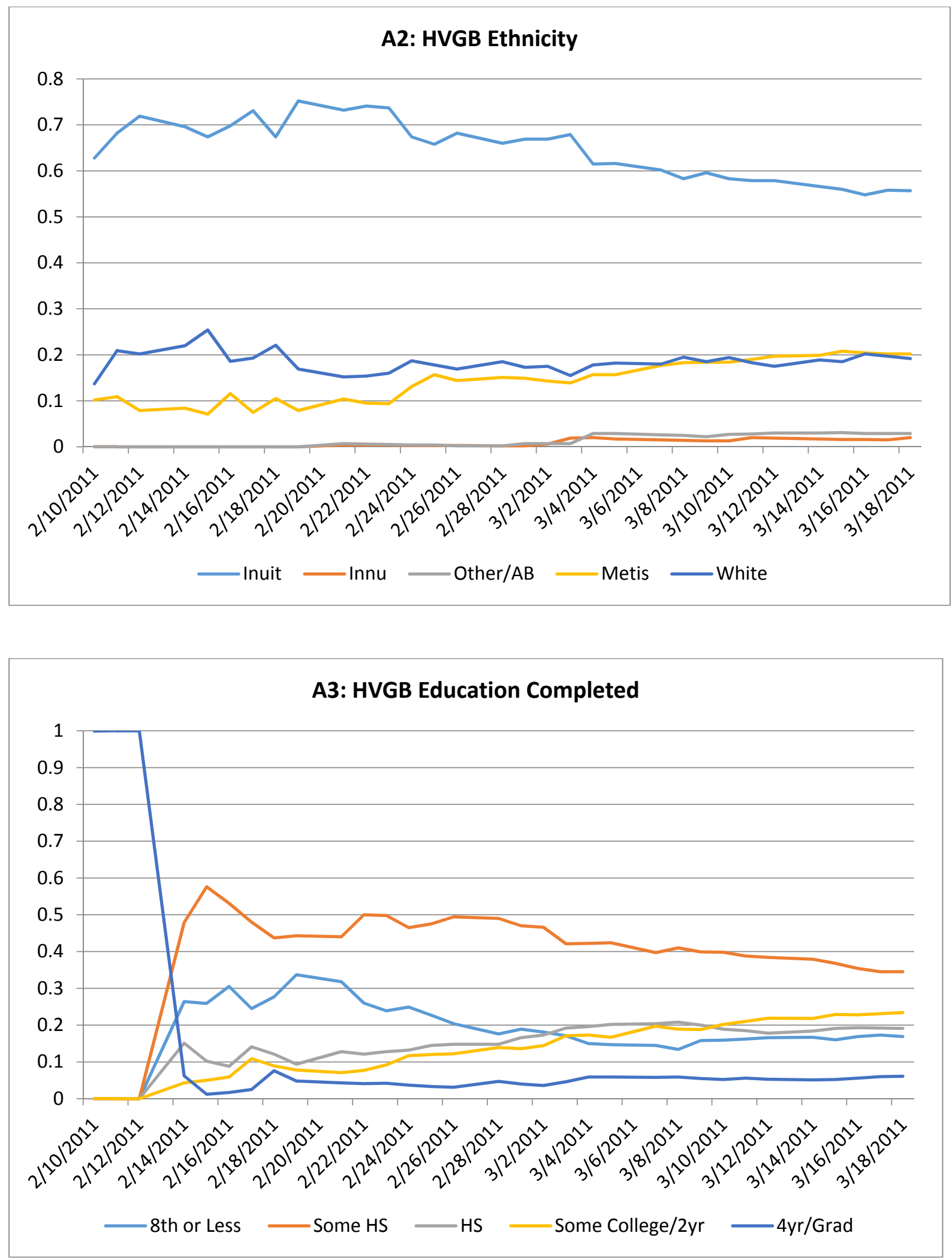

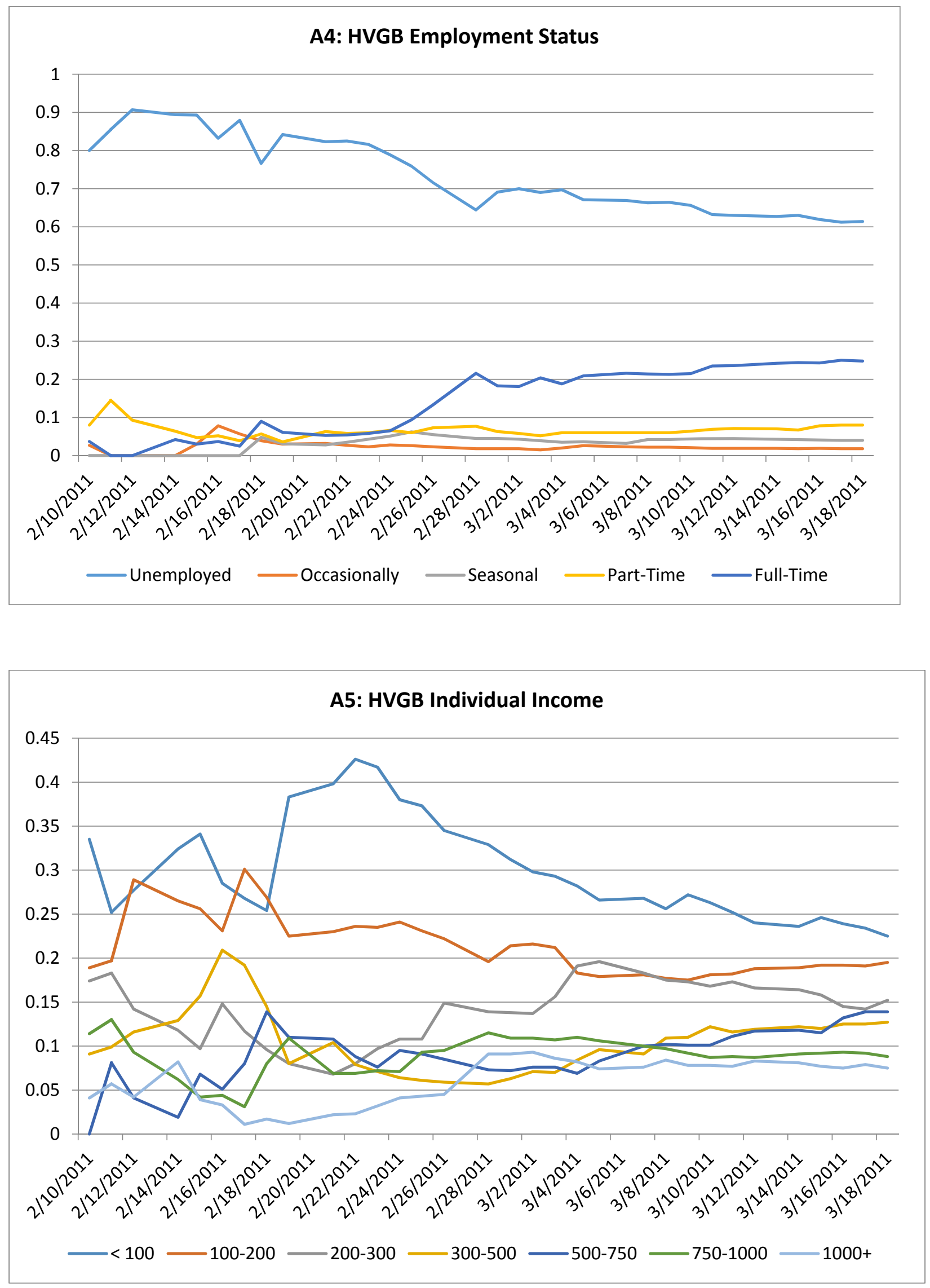

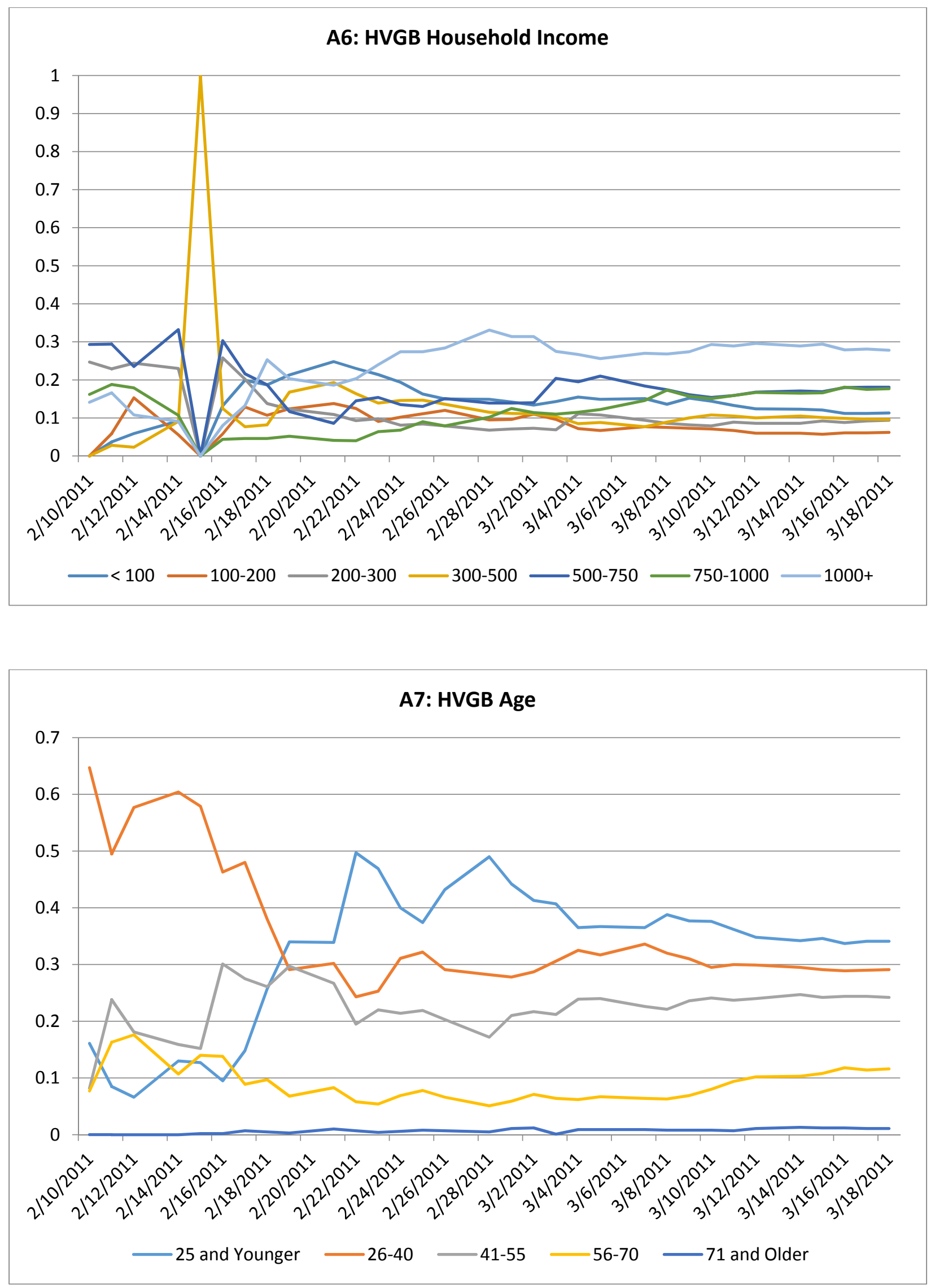

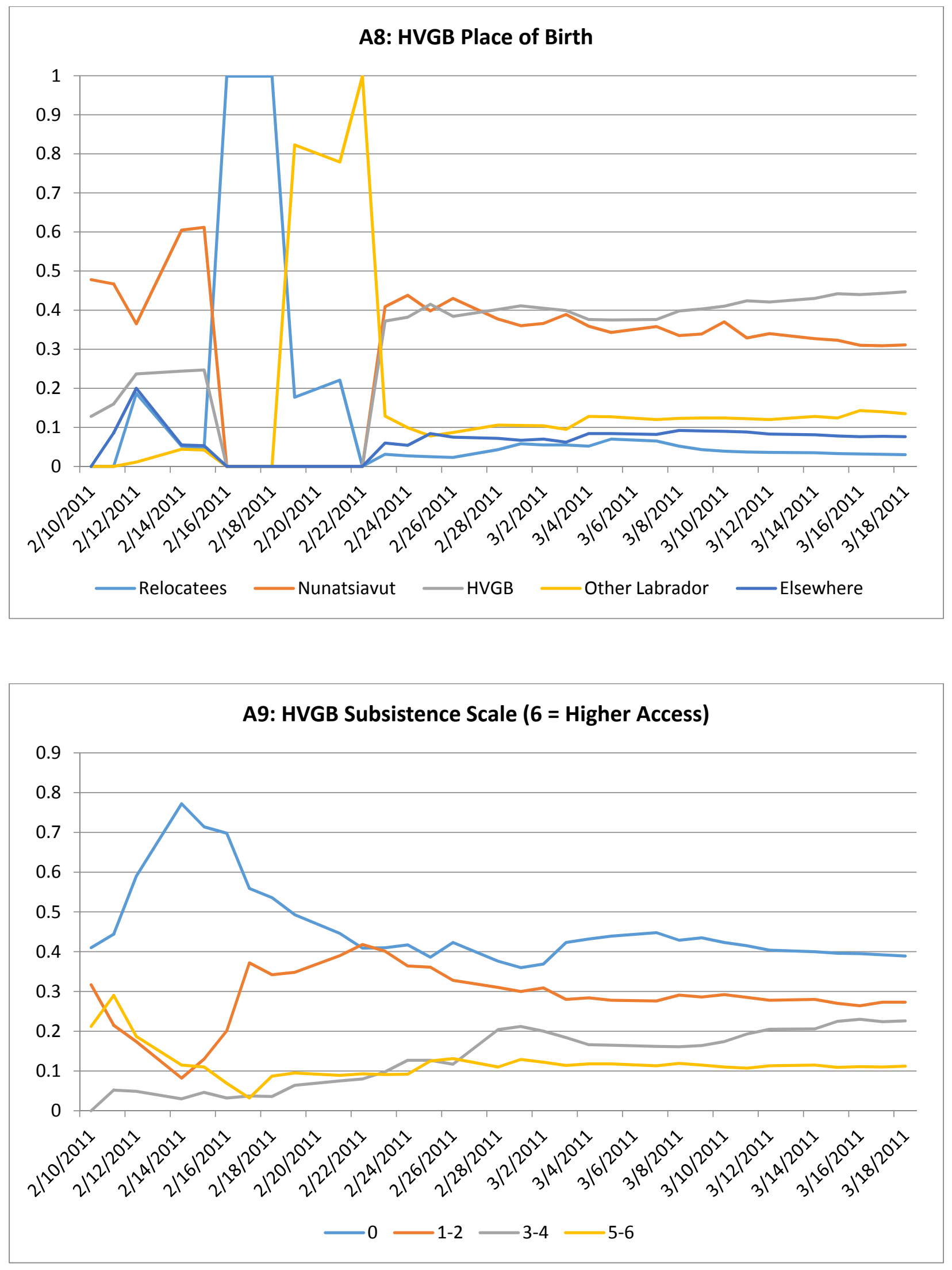